\title{
Surface Stability Test Plan for Protective Barriers
}

\author{
M. W. Ligotke
}

January 1989

Prepared for the U.S. Department of Energy under Contract DE-AC06-76RLO 1830

Pacific Northwest Laboratory

Operated for the U.S. Department of Energy by Battelle Memorial Institute 


\title{
DISCLAIMER
}

This report was prepared as an account of work sponsored by an agency of the United States Government. Neither the United States Government nor any agency thereof, nor Battelle Memorial Institute, nor any or their employees, makes any warranty, expressed or implied, or assumes any legal liability or responsibility for the accuracy, completeness, or usefulness of any information, apparatus, product, or process disclosed, or represents that its use would not infringe privately owned rights. Reference herein to any specific commercial product, process, or service by trade name, trademark, manufacturer, or otherwise does not necessarily constitute or imply its endorsement, recommendation, or favoring by the United States Government or any agency thereof, or Battelle Memorial Institute. The views and opinions of authors expressed herein do not necessarily state or reflect those of the United States Government or any agency thereof.

\author{
PACIFIC NORTHWEST LABORATORY \\ operated by \\ BATTELLE MEMORIAL INSTITUTE \\ for the \\ UNITED STATES DEPARTMENT OF ENERGY \\ under Contract DE-AC06-76RLO 1830
}

\begin{tabular}{|c|c|}
\hline \multicolumn{2}{|c|}{ Printed in the United Stales of America } \\
\hline \multicolumn{2}{|c|}{ Available from } \\
\hline \multicolumn{2}{|c|}{ National Technical Information Service } \\
\hline \multicolumn{2}{|c|}{ United States Departmenl of Commerce } \\
\hline \multicolumn{2}{|c|}{5285 Port Royal Road } \\
\hline \multicolumn{2}{|c|}{ Springfield, Virginia 22161} \\
\hline \multicolumn{2}{|c|}{ NTIS Price Codes } \\
\hline \multicolumn{2}{|c|}{ Microfiche A01 } \\
\hline \multicolumn{2}{|c|}{ Printed Copy } \\
\hline & Price \\
\hline Pages & Codes \\
\hline $00 \dagger-025$ & $\mathrm{~A} 02$ \\
\hline $026-050$ & A03 \\
\hline $051-075$ & $\mathrm{~A} 04$ \\
\hline $076-100$ & $\mathrm{~A} 05$ \\
\hline $101 \cdot 125$ & $A 06$ \\
\hline $126-150$ & $\mathrm{~A} 07$ \\
\hline $151-175$ & $\mathrm{AOB}$ \\
\hline $176-200$ & $\mathrm{~A} 09$ \\
\hline $201 \cdot 225$ & A10 \\
\hline $226-250$ & AIT \\
\hline $251 \cdot 275$ & A12 \\
\hline $276-300$ & A13 \\
\hline
\end{tabular}




\section{SURFACE STABILITY TEST PLAN FOR PROTECTIVE BARRIERS}

M. W. Ligotke

January 1989

Prepared for the

U.S. Department of Energy under Contract DE-AC06-76RLO 1830

\footnotetext{
Pacific Northwest Laboratory

Richland, Washington 99352
} 


\section{SUMMARY}

Natural-material protective barriers for long-term isolation of buried waste have been identified as integral components of a plan to isolate a number of Hanford defense waste sites (DOE 1987a). Standards currently being developed for internal and external barrier performance will mandate a barnier surface layer that is resistant to the eolian erosion processes of wind erosion (deflation) and windborne particle deposition (formation of sand dunes). Thus, experiments are needed to measure rates of eolian erosion processes impacting those surfaces under different surface and climatological conditions. Data from these studies will provide information for use in the evaluation of selected surface layers as a means of providing stable cover over waste sites throughout the design life span of protective barriers.

The multi-year test plan described in this plan is directed at understanding processes of wind erosion and windborne particle deposition, providing measurements of erosion rates for models, and suggesting construction materials and methods for reducing the effect of long-term eolian erosion on the barrier.

Specifically, this plan describes possible methods to measure rates of eolian erosion, including field and laboratory procedures. Advantages and disadvantages of laboratory (wind tunnel) tests are discussed, and continued wind tunnel tests are recommended for wind erosion studies. A comparison between field and wind tunnel erosive forces is discussed. Plans for testing surfaces are described. Guidance is also presented for studying the processes controlling sand dune and blowout formation; however, because these processes are not well understood, the best approach is not certain and may include a combination of laboratory and field studies.

An initial series of wind tunnel tests, performed to develop test procedures, provided information on the relative stability of three soil and gravel mixtures. Mixtures containing 30 and $50 \%$ gravel $(0.7-\mathrm{cm}$ gravel size) were found to provide better resistance to wind erosion than a surface containing $30 \%$ gravel $(1.6-\mathrm{cm}$ size). Details of these tests are presented in Ligotke (1988). The proposed studies will complete the investigation of the influence of gravel size and percentage of surface layer, and will investigate the influence of crusts, vegetation, soil moisture content, and other surface conditions on rate of erosion under extreme climatological conditions. Planned studies of windborne deposition of sand, including sand dune formation over the 
barrier are also described in this plan. Such an occurrence could reduce barrier performance by displacing natural plant species and reducing the capacity of the plant cover to dry the surface layer water reservoir through evapotransporation. A sand cover would also limit natural evaporation of surface water trapped in the reservoir. 


\section{CONTENTS}

SUMMARY ..................... . . . . . . . . . .

1.0 INTRODUCTION . . . . . . . . . . . . . . . . 1.1

2.0 BACKGROUND . . . . . . . . . . . . . . . . . . . . 2.1

2.1 PROJECT OBJECTIVES AND SCOPE . . . . . . . . . . . . . . . 2.1

2.2 PROTECTIVE BARRIER SURFACE CHARACTERISTICS . . . . . 2.2

2.3 EOLIAN PROCESSES . . . . . . . . . . . . . . . . . . 2.4

2.3.1 Wind Erosion/Deflation. . . . . . . . . . . . . . . . . . 2.5

2.3.2 Sand Transport and Deposition . . . . . . . . . . . . 2.6

2.4 WIND TUNNEL MODELING $\ldots \ldots \ldots \ldots$

3.0 WIND EROSION. . . . . . . . . . . . . . . . . . . . . . . . . 3.1

3.1 CLIMATE AND EXTREME WIND EVENTS . . . . . . . . . . . . 3.1

3.2 EXPERIMENTAL DESIGN . . . . . . . . . . . . . . 3.9

3.2.1 Soil and Gravel Mixtures . . . . . . . . . . . . . . . . 3.10

3.2.2 Surface Crusts and Soil Moisture Content . . . . . . . . . 3.14

3.2.3 Vegetation . . . . . . . . . . . . . . . . 3.15

3.2.4 Animal Burrow Mounds . . . . . . . . . . . . . . . . 3.16

3.2.5 Microterrain . . . . . . . . . . . . . . . . . . . 3.17

3.2.6 Field Companison Tests . . . . . . . . . . . . . . . . 3.17

3.3 TEST SURFACE PREPARATION . . . . . . . . . . . . . . . . 3.18

3.4 TEST PROCEDURES . . . . . . . . . . . . . . . . . . . 3.18

3.5 DATA ANALYSIS . . . . . . . . . . . . . . . . . . . 3.19

4.0 SAND TRANSPORT AND DEPOSITION . . . . . . . . . . . . . . 4.1

4.1 WIND PATTERNS: BOUNDARY LAYERS AND EDGE EFFECTS . . 4.1

4.2 EXPERIMENTAL DESIGN . . . . . . . . . . . . . . 4.2 
5.0 FACILITIES AND PROJECT PLANNING . . . . . . . . . . . . . 5.1

5.1 WIND TUNNEL FACILITY . . . . . . . . . . . . . . 5.1

5.2 SCHEDULE AND COSTS . . . . . . . . . . . . . . . . 5.3

5.2 REPORTING .................... 5.5

6.0 SAFETY AND QUALITY ASSURANCE . . . . . . . . . . . . . . 6.1

7.0 REFERENCES . . . . . . . . . . . . . . . . . . 7.1 


\section{EIGURES}

2.1 Conceptual Design of Multilayer Protective Barrier. . . . . . . . . . . 2.3

3.1 Hourly and Monthly Average Wind Speeds for Five Elevations at the Hanford Site--January Through June. . . . . . . . . . . . . 3.2

3.2 Hourly and Monthly Average Wind Speeds for Five Elevations at the Hanford Site--July Through December . . . . . . . . . . . . 3.3

3.3 Peak Wind Gust Return Period Probability Diagram, Based on Records

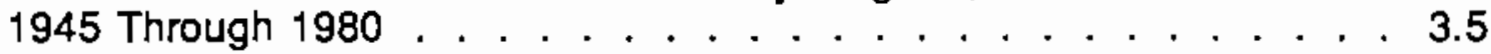

3.4 Typical Hanford Site Wind Speed Boundary Layers at $0100 \mathrm{hr}$ and $1200 \mathrm{hr}$. . . . . . . . . . . . . . . . 3.7

3.5 Friction Velocities Measured Over a Plastic Spray-Coated $30 \% 0.7-\mathrm{cm}$ Gravel and Soil Surface with a Roughness Height of $0.41 \pm 0.08 \mathrm{~mm}$ . . 3.8

5.1 PNL Aerosol Wind Tunnel Research Facility. . . . . . . . . . . . . . . 5.2

\section{TABLES}

3.1 Percent Frequency of Monthly and Annual Wind Speed at $50 \mathrm{ft}(15.2 \mathrm{~m})$ Elevation . . . . . . . . . . . . . . . . . . . . 3.4

3.2 Proposed Tests of Bare Mixed Soil and Gravel Surfaces . . . . . . . 3.12

5.1 Schedule and Costs for Protective Barrier Surface Stabilization Tasks . 5.4 


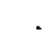




\subsection{INTRODUCTION}

Protective barriers have been identified as integral components of plans to isolate defense waste on the Hanford Site (DOE 1987a). The use of natural materials to construct protective barriers over waste sites is being considered. Design requirements for protective barriers include preventing the exposure of buried waste, whether by natural or human-caused disturbances, and restricting the penetration or percolation of surface waters through the waste zone. A barrier design proposed for arid climates such as Hanford (DOE 1987b) employs a series of layers, including gravel and riprap, sand, an impermeable layer, and soil and gravel mixtures.

Adams and Wing (1986) reported that various aspects of protective barrier performance have been evaluated with both mathematical models and field tests, that these evaluations were continuing, and that additional investigations were planned. Resistance of the barrier surface to eolian forces was listed by the authors as one necessary area of study; both deflation because of wind erosion, and the opposite effect, deposition of sand, potentially could reduce the effectiveness of the barrier to maintain adequate cover and prevent water infiltration at waste sites.

In support of barrier development, Pacific Northwest Laboratory (PNL)(a) contracted with the U.S. Department of Energy (DOE) through Westinghouse Hanford Company to study the effects of wind erosion on mixtures of soil and gravel. Wind tunnel tests were used to investigate the erosive effects of wind forces on proposed surface layers for protective barriers. Mixed soil and gravel surfaces were prepared and tested for resistance to wind erosion at the PNL Aerosol Wind Tunnel Research Facility. These were the first of a series of planned tests to investigate surface deflation caused by suspension of soil from various surface configurations, and were used to test the suitability of the wind tunnel to make surface deflation measurements. Results of these preliminary tests are described in Ligotke (1988).

Continued wind tunnel tests proposed in this test plan will investigate the resistance of various surface conditions to wind erosion, and are based, in part, on information presented in an unpublished test plan by Carlson. Studies of deposition

(a) Operated for the U.S. Department of Energy by Battelle Memorial Institute under Contract DE-AC06-76RLO 1830. 
processes, primarily with respect to sand displacement of fine soils and formation of sand dunes, are proposed based on unpublished work of Kasper and Glantz. In addition, air flow patterns and boundary layers over elevated protective barrier surfaces should be investigated to determine the possible need for windbreaks and to define potential edge effects. Completion of these tasks will provide information for the companion task of protective barrier modeling and will aid engineening considerations in planning to construct protective barriers.

Planning, testing, and analysis phases of wind erosion tasks are coordinated with other tasks supporting the development of protective barners. The other tasks include climate-change predictions, field studies (admix test plots, natural analogs, and evapotranspiration), and modeling efforts (erosion, UNSAT, BIOPORT). Results of this project are important for the development of a suitable design for the barrier surface, but must be considered along with results of the other tasks. For example, water storage capacity, and plant growth and viability in suitable wind-resistant surface layers should be determined. And, although fractional gravel covers prevent soil drying, and thus may promote plant growth, excessive covers reduce plant community viability and restrict soil moisture evaporation. Wind-resistant surfaces must still be able to sustain plant growth and allow drying. Burrowing animals are also thought to present a major destructive force at the barrier surface, and their activities should be considered.

Section 2.0 of this plan describes the specific scope of the project and provides descriptions of barrier surface characteristics, wind erosion, sand transport and deposition, and wind tunnel modeling. The wind tunnel tests for wind erosion are described in Section 3.0. Sand transport and deposition tasks are outlined in Section 4.0. Facilities and project planning details are included in Section 5.0. Section 6.0 describes safety and quality assurance procedures. 


\subsection{BACKGROUND}

This section outlines the project scope, describes the proposed general composition of the surface layer for protective barriers, and discusses wind erosion, sand transport and deposition, and the advantages and disadvantages of physical (wind tunnel) models.

\subsection{PROJECT OBJECTIVES AND SCOPE}

The planned scope of work includes expanding present experiments to consider both deflation and deposition. Soil and gravel mixtures, surface crusts, vegetation, animal burrow mounds, microterrain structure, and soil moisture content will be considered to determine the potential for surface deflation as influenced by average and extreme wind events. In addition, tests of the suitability of using a wind tunnel to simulate natural wind erosion conditions will continue; the effects of test bed length, air turbulence, and terrain microrelief will be considered. Studies of deposition processes may include an analysis of the boundary layer over barnier surfaces and the potential for sand deposition and sand dune formation. Results from the deposition tasks may provide information on potential effects of locating barriers near certain topographical features on the Hanford Site with respect to sand deposition and sand dune formation. They may also describe windbreaks to be located upwind or on top of above-ground barriers. Detailed plans for the deposition-related studies suggested in this test plan are not presented; however, preliminary cost and schedule estimates are provided for the development of detailed plans and completion of deposition studies. One objective of eolian land form studies should be to determine the origin of blowout structures (i.e., what type and magnitude of blowout is formed under varying soil, wind, and topographical conditions) and the extent of sand particle transport from a blowout. If it is likely that blowouts will form adjacent to barriers, it is then possible that they will provide a source for subsequent transport and deposition of sand to the surface of the barriers. Applying gravel mulch or other surface cover over sandy soils located upwind from the barriers along prevailing wind directions may be an appropriate control measure.

Results of tasks described in this test plan both influence and are influenced by other aspects of the barrier design. For example, the surface layer must be maintained to provide resistance to deflationary forces and to protect the fine soil water storage 
reservoir portion of the barrier. Exposure of lower-barrier layers such as geotextiles or coarse riprap could enhance infiltration and must be prevented. Plant community viability in soil and gravel mixtures and reduced surface evaporation under gravel covers limit the mass fraction of gravel that may be used, because wind-resistant surfaces must still be able to sustain plant growth and because surface evaporation may be an important route for releasing surface water. Burrowing animals are anticipated to be, primarily, a destructive force on the barrier; the activity of these animals and the amount of soil they bring to the surface (then subject to wind erosion) is partially determined by the presence of vegetation and may be related to the soil and gravel composition. In addition, excessive deposition of windborne sand particles would reduce the capacity of the fine-soil reservoir. This condition would also tend to increase water infiltration by providing a capillary break between the fine-soil reservoir and the surface, thus reducing the effectiveness of surface evaporation. Formation of sand dunes over the protective barrier could also displace desired species of plants, perhaps by raising the elevation of the surface so that the water reservoir may be out of reach of plant roots, thus reducing levels of evapotransporation. The potential for such transport and deposition of sand exists on the Hanford Site, and two sets of sand dune fields and several blowouts have been identified in an unpublished study by Kasper and Glantz. The cause of the blowouts and the detailed characteristics of soil particle size and wind patterns at these sites have not been determined.

\subsection{PROTECTIVE BARRIER SURFACE CHARACTERISTICS}

The design of a protective barrier for waste-site containment must include a surface that will be stable and continue to isolate the waste over a 10,000 -year life span. A detailed description of the current barrier design proposed for the Hanford Site is provided in Adams and Wing (1986); a sketch of the layered design is shown in Figure 2.1.

Several characteristics of the surface layer are important in defining the optimum erosion- and deposition-resistant protective barrier, including: 1) soil type and particle size; 2) gravel size, shape, and percentage of the surface layer; 3) soil moisture content and density; 4) presence or absence of an established plant canopy or a plant root structure (especially following a range fire); and 5) presence or absence of surface crusts, including desert pavement, lichen-cryptogamic, and chemical crusts. 

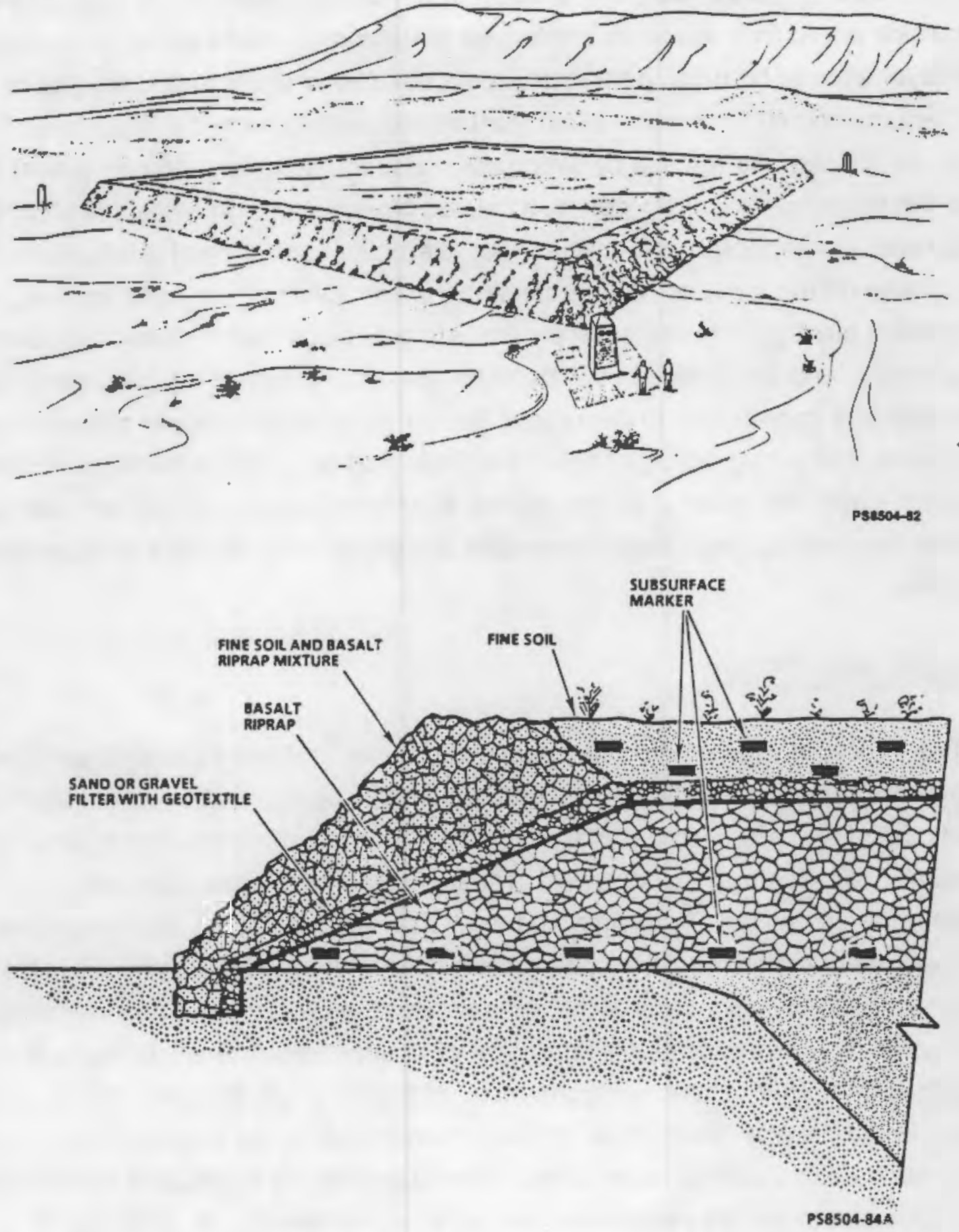

ElGURE 2.1. Conceptual Design of Multilayer Protective Barrier (After Adams and Wing 1986) 
Determining suitable candidate surfaces requires consideration of many variables, including the potential degradation of the surface over the life span of the barrier, which would limit use of an impervious surface over waste sites. If a natural surface layer were to be used, it must provide a suitable environment to support a viable plant community and retain water from rainfall and snowmelt in the fine-soil reservoir for subsequent release by evaporation and transpiration. Mixing gravel with soil has the potential for limiting deflation caused by wind erosion while still providing a surface with the necessary capabilities. An alternative approach of placing a thick layer of gravel on the surface, while protecting the soil surface from wind erosion, would prevent plant growth and severely limit surface evaporation, thus enhancing water infiltration and drainage into the barrier's interior. However, a thick gravel cover, while temporarily contributing to decreased barrier performance, would probably not remain stable over a long period of time. It is likely that the combined effects of freezethaw, shrink-swell, root pressures, and animal burrowing would produce a mixed soil and gravel morphology, regardless of whether the gravel was initially a surface layer or an admix.

\subsection{EOLIAN PROCESSES}

The effects of wind erosion and deposition on natural and cultivated surfaces have been the subject of many years of study, primarily by agricultural scientists. The potential cost of the loss of valuable topsoil has warranted sustained investigations of the erosion, or deflation, of soil surfaces. These studies have attempted both to understand the processes of deflation and to devise methods of stabilizing surfaces from the effects of deflation. A second problem related to erosion of surfaces more recently has led to investigations of the rates of resuspension of materials deposited to various surfaces. For example, resuspension of radioactive materials deposited during fallout from atmospheric weapons tests, or from postulated power plant accidents, could provide health risks and has been studied extensively. Other materials such as mill tailings, waste sites, mineral (asbestos) fibers, and certain toxic or hazardous materials can also present resuspension concerns. A summary of resuspension data was provided by Sehmel $(1980,1984)$.

The effects of eolian processes on the performance of the protective barrier are grouped into two categories, deflation and deposition. Deflation effects include the 
loss of surface soil, especially during extreme wind events, resulting in a gradual lowering of the surface level. Another potentially significant form of deflation involves the formation of surface depressions such as blowouts. Examples of these may be seen in locations below and on the 200-Area plateau at Hanford. These structures form because of high wind forces directed toward the ground in the wake of nearby large objects, or may form more spontaneously if stabilizing plants are dislodged and if local or upwind soils contain a large percentage of sand. In addition to deflation caused by normal weathering processes, deflation may be enhanced by surface disturbances, whether human-caused or the result of burrowing animals. Effects of sand particle deposition include displacement of fine-grained surface soils with deposits of windborne sand particles and the formation of sand dunes. Deposition of other windblown particles, such as volcanic ash deposition can be important in longterm climatic scenarios, but will not be considered in the present testing.

\subsubsection{Wind Erosion/Deflation}

Studies performed over past decades have revealed air and surface characteristics that are of primary importance to the study of wind erosion. A partial listing of these studies includes Bagnold (1941); Chepil and Milne (1941); Chepil (1945a, 1945b, 1950); Zingg (1949); Chepil and Woodruff (1963); Chepil, Armbrust, and Siddoway (1964); and Logie $(1981,1982)$. Important atmospheric properties and characteristics outlined in these studies include wind speed, turbulence, density, and viscosity. The authors note important surface soil properties and characteristics as soil moisture content, vegetation, gravel, or other material, topography, soil structure, and surface roughness. Soil characteristics influencing erodibility include composition (clay, silt, sand, and organic matter); particle size distribution (including gravel mixtures); and the presence of non-erodible aggregates or clods.

Three processes are involved in the transport of soil particles by wind erosion: surface creep, saltation, and suspension. Surface creep includes relatively large particles, generally on the order of $1 \mathrm{~mm}$ in diameter that are transported in the direction of the wind vector by sliding or rolling. In addition, surface creep may be considered to include larger particles, even gravel particles, that are influenced by wind forces, and in turn, influence the transport of other particles. Under sufficiently high wind forces, gravel particles may be dislodged and slide or roll downwind. At lower wind speeds, gravel may influence the local distribution of wind forces by 
protruding into the air-flow boundary layer to a greater extent than the surrounding surface and deflecting wind forces toward the surface. These forces may dislodge smaller soil particles, which may eventually dislodge support for the gravel particle and cause it to rotate to a new position. Rotations perpendicular to the wind vector were observed by Ligotke (1988); gravel was observed to oscillate from one side to the other as support was eroded. Logie (1982) observed movement of spheres and gravel into the direction of the wind vector when placed on a flat sand surface.

Saltation of large particles is a second transport process. Saltation occurs when wind-induced low pressure forces over a particle are sufficient to overcome attractive forces between the particle and the surface and the gravitational force on the particle. Saltation acts primarily on particles on the order of $100 \mu \mathrm{m}$ in size and is characterized by an initial vertical leap followed by transport back to the surface at a shallow angle of approximately $15^{\circ}$. The impact of saltating particles on surfaces may be a major driving force influencing wind erosion. The kinetic energy of a saltating particle is significant because of its large impact velocity and greater-than-average particle mass. On impact, such particles have been shown to enhance suspension of soil particles. Over a long surface, an avalanching effect may occur. Under the influence of very high wind speeds, gravel may be transported in a manner similar to that of saltating soil particles. Although soil particles may attain an initial height of about $1 \mathrm{~m}$, gravel particles may be expected to lift only a few centimeters or less off the surface.

Suspension of soil particles represents the majority of the loss of surface mass. Suspension is directly influenced by wind as is saltation; however, suspension is also influenced by both surface creep and saltation. Suspension of particles often occurs in bursts following dislodgement of surface gravel, or following the impact of saltating particles. Particles transported by suspension are typically about $100 \mu \mathrm{m}$ or less.

\subsubsection{Sand Transport and Deposition}

Eolian research has historically concentrated on wind erosion rather than deposition of windborne particles. Of deposition studies completed, most were concerned with short-term deposition of specific materials to various surfaces. Basic information on site-specific formation of sand dunes is therefore limited. Preliminary, unpublished work by Kasper and Glantz provided a description of the sand particle 
transport potential and described various dune structures found on the Hanford Site. The researchers concluded that climatological conditions on site are currently sufficient to support eolian activity, including transport of sand particles. The lack of extensive sand dunes (two sand dune fields have been identified at Hanford) and other eolian features, such as blowouts on the 200-Area plateau, was attributed to either adequate surface stability, or a lack of suitably sized material (sand).

Two conditions are expected to provide the potential for sand dune formation on the surface of protective barriers: insufficient surface stability and availability of sandsized material upwind of the protective barrier, and the configuration of the barrier surface. If stabilizing vegetation on or in the vicinity of the barrier is removed by an event such as a range fire, rates of sand transport may be increased and encourage the formation of sand dunes. Also, wind-flow patterns may favor deposition of sand particles. These flow patterns might include edge effects of above ground barrier surfaces or influences of the surrounding topography.

The first requirement in defining the potential for sand particle deposition to the surface of the barrier is determining the nature of wind forces acting on the barrier, specifically the nature of the wind boundary layers over the barrier. Regions of low velocity would be potential sites for deposition of sand particles under the influence of gravity, and areas of high velocities directed toward the surface could develop blowouts. Potential blowout formation in sandy soil may be more likely than formation on the silt-loam of the barrier surface; such an occurrence upwind of a protective barrier may act as a source of windborne sand particles that may subsequently deposit on the barrier. Control of these occurrences may be required and could include laying the barrier surface layer mixture over upwind sites, planting ground-stabilizing vegetation, or constructing windbreaks.

Cal et al. (1983) performed wind tunnel tests of reduced-scale porous storage piles to investigate the effect of pile configuration and the use of windbreaks to reduce the erosive forces over the surface. Control of wind forces over surfaces, primarily using windbreaks, was also studied by Chen and Soo (1983) and Heinsohn and Megherhi (1986). The procedures developed in these studies may be applicable to the protective barrier; various barrier shapes (configurations) may be investigated in a wind tunnel to develop a shape having appropriate wind-flow characteristics both over the surface and at the edges. Field data on wind boundary layers upwind of, at the 
edge of, and over prototype, full-scale protective barriers, or similar waste site covers at the 200 Area should be acquired, as such structures are constructed, and used to augment reduced-scale wind tunnel studies. Development of windbreaks may be important; however, such structures would require special consideration because of the long design lifetime of the barrier.

Wind patterns will be primarily influenced by climatological conditions, including wind direction and intensity; however, the shape or configuration of the (aboveground) barrier and the surrounding topography will also affect the pattern and intensity of wind forces on the barrier. The leading or trailing edges of the barrier along prevailing wind vectors may be critical areas for controlling sand dune and blowout formation.

\subsection{WIND TUNNEL MODELING}

Comparison tests of different surface configurations with respect to deflation require that similar erosive forces be applied to each surface. These conditions are difficult to achieve in the field where high wind speeds are infrequent, non-uniform in direction, and inconsistent. In a wind tunnel, however, wind forces may be replicated from test to test, are controlled, and provide a basis for comparing various surfaces.

Differences between laboratory and field testing must be considered when absolute measurements of deflation are attempted in a wind tunnel. Surfaces or surface crusts may be manufactured in the laboratory or obtained in the field and transported to the laboratory. Although boundary layer depths are much less in wind tunnel experiments than under actual field conditions, this difference does not affect measurements of deflation because the erosive forces at surfaces are related to surface shear forces, which are in turn indicated by surface roughness and friction velocity. Multiple-direction weathering of surfaces in the field, as influenced by prevailing winds, is different than the single-direction weathering in standard wind tunnels. Although not anticipated to be important, the effect of multiple-direction weathering could be investigated in a wind tunnel by rotating the surface within the test section. 
Another difference between laboratory and field conditions includes the unsteady nature of natural winds. Large-scale turbulence, such as gusts or eddies near objects, may be responsible for initiating of deflationary processes such as creep, saltation, and particle suspension in the field. For example, a normally stable surface may deflate during exposure to a given mean wind speed because of the occurrence of wind gusts that bring large erosive forces to ground level. Wind tunnel experiments with steady, sustained wind speeds equivalent to the gusts (i.e., equal friction velocities) may be used to investigate the effect of the gusts, or the gusts may be reproduced mechanically in a wind tunnel.

Of possibly more importance with respect to differences between laboratory and field is the length of the surface over which erosive forces act. Saltation has often been determined to have an avalanching effect on wind erosion. Particles are suspended and then fall back to the surface where their impact causes other particles to suspend. Similar increases in deflation occur because of surface creep. Because of the limited length of the exposed surface in wind tunnels, any avalanching effect would be conservative; measured rates of deflation may be less than those actually occurring in the field. The difference may be accounted for by comparing field and wind tunnel measurements. Several techniques exist for measuring the effect of avalanching particles in wind tunnels. For example, the length of the test bed may be altered; a measure of larger deflation rates over the longer surfaces would indicate the effect of avalanching particles. Another approach would be to inject a characterized saltation force, perhaps using spherical glass beads, and then compare the resulting soil particle suspension with and without induced saltation. This approach has been used by Fairchild and Tillery (1982) and Borrmann and Jaenicke (1987). Saltation was shown to increase soil particle suspension rates, but its influence on surface stabilization, or the ability of the surface to develop a protective crust was not investigated. The effect of saltation is anticipated to decline as surface crusts form during surface aging under natural climatic conditions. 



\subsection{WIND EROSION}

The capacity of wind to transport soil particles from surfaces, and thus to cause deflation, is strongly influenced by the magnitude and form of the wind forces incident on the surface. To predict and model the potential for wind erosion from the surface of the protective barrier requires that these wind speed data be collected as well as information on other seasonal cycles, such as temperature, precipitation, and plant and animal influences. This section describes wind tunnel tests proposed to investigate various combinations of surface characteristics, wind forces, and plant and soil interactions. The result of these tests will be data sets for comparison of relative resistance to wind erosion of various surface mixtures under wide-ranging climatic and surface conditions, and also for use in the subsequent development of predictive models of wind erosion rates.

\subsection{CLIMATE AND EXTREME WIND EVENTS}

Understanding the wind forces present at the Hanford Site is required for comparison tests of various surfaces and surface configurations. The magnitude and duration of wind events are important to the development of predictive models for soil transport and surface deflation. Also important is understanding the relationship between average wind events and turbulence, specifically peak gust frequencies, speeds, and durations. Wind direction information is of less importance with respect to wind erosion, but is necessary for related studies of sand transport and deposition on barrier surfaces (see Section 4.0). Other climatological parameters such as seasonal precipitation and temperature cycles (including freeze-thaw cycles) strongly influence wind erosion potential, primarily by affecting soil moisture content (SMC) and the development and maintenance of surface crusts, and must be considered in developing predictive models.

More than 40 years of detailed meteorological data have been collected at the Hanford Site. Stone et al. (1983) summarized these data for 1946 to 1980 . Hourly average wind speeds from these studies for each month are shown in Figures 3.1 and 3.2 for five elevations: 2, 15, 30,61, and $122 \mathrm{~m}(7,50,100,200$, and $400 \mathrm{ft})$. Hourly and seasonal variations in mean wind speed and boundary layer shape are shown in 

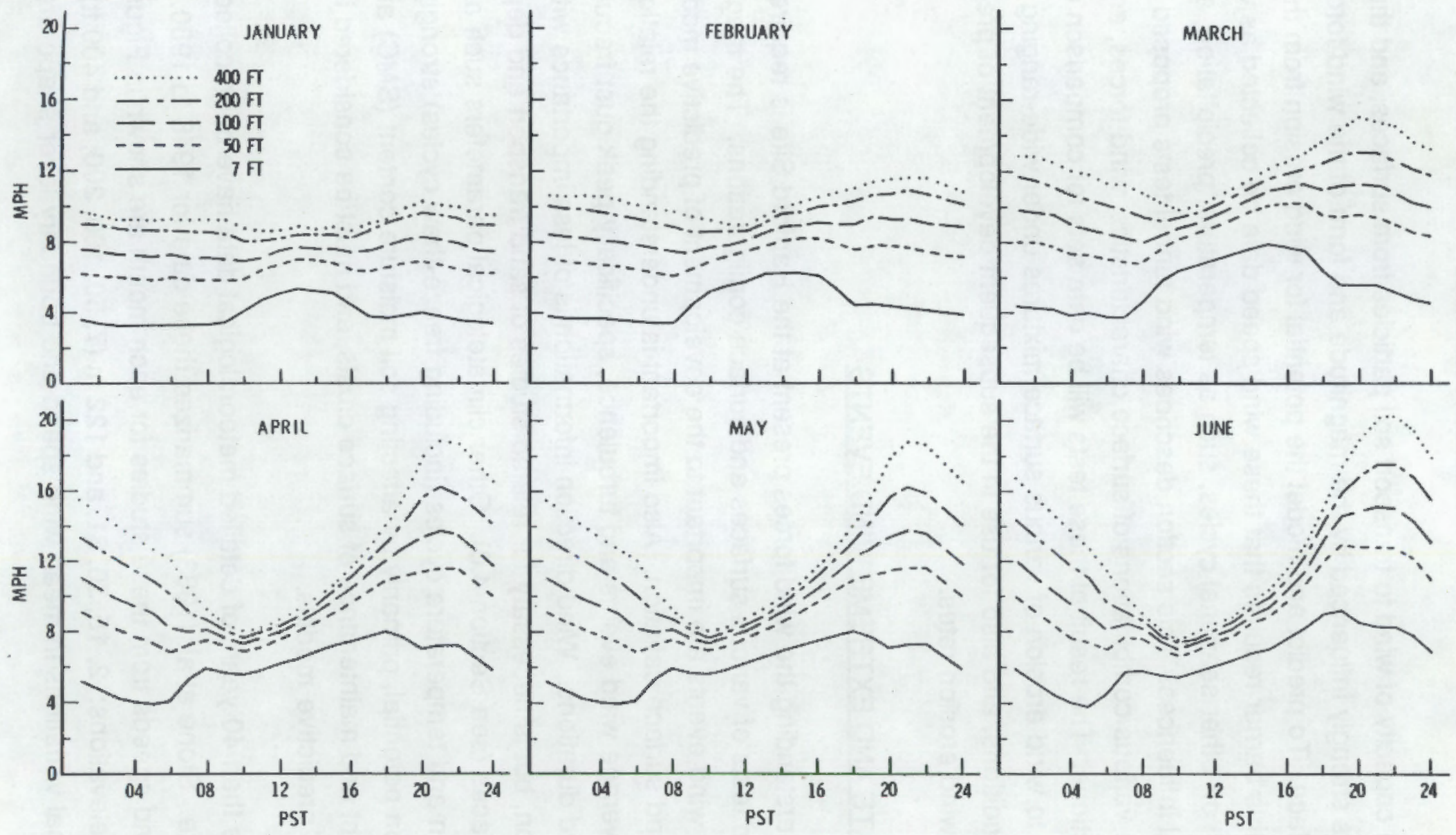

FlGURE 3.1 Hourly and Monthly Average Wind Speeds for Five Elevations at the Hanford Site--January Through June; PST = Pacific Std. Time (from Stone et al. 1983) 

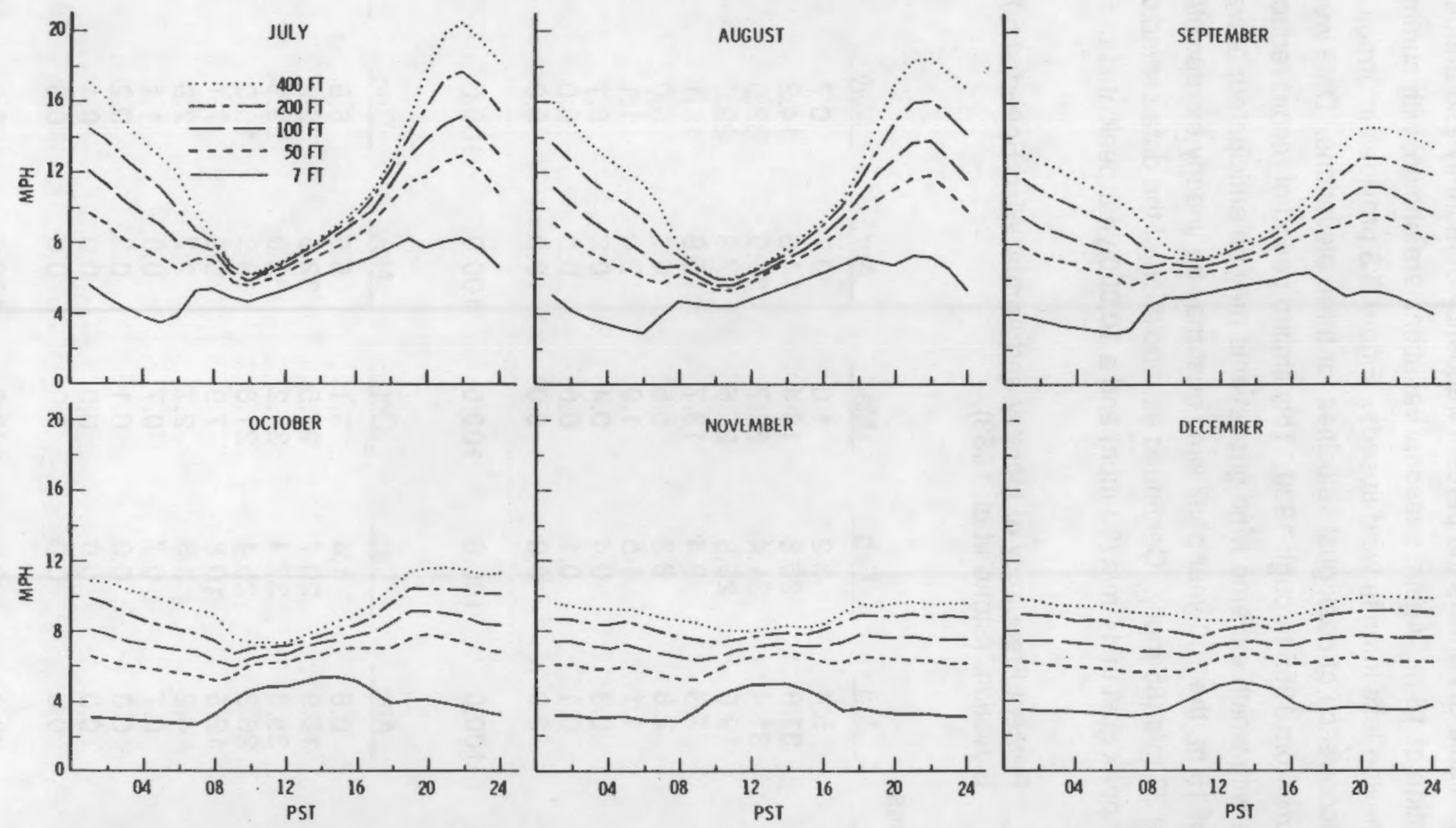

FlGURE 3.2 Hourly and Monthly Average Wind Speeds for Five Elevations at the Hanford Site--July Through December; PST = Pacific Std. Time (from Stone et al. 1983) 
the figures. Table 3.1 shows the percent frequency of monthly and annual wind speed at an elevation of $15 \mathrm{~m}$. Again, seasonal variations are shown, with summer months generally having less intense wind speeds. Figure 3.3 provides information on the period of occurrence of peak gust velocities for three elevations. Data were obtained for this figure from 1955 through 1980. This limited period of record reduces the confidence with which extreme wind gust events may be anticipated; however, at an elevation of $15 \mathrm{~m}$, the 100-year peak wind gust may be linearly extrapolated from the figure to be $38 \mathrm{~m} / \mathrm{s}(85 \mathrm{mph})$. Continued extrapolation of the data set indicates a 1,000-year peak gust of $44 \mathrm{~m} / \mathrm{s}(99 \mathrm{mph})$ and a 10,000-year peak gust of $51 \mathrm{~m} / \mathrm{s}$

IABLE 3.1. Percent Frequency of Monthly and Annual Wind Speed at $50 \mathrm{ft}(15.2 \mathrm{~m})$ Elevation (Stone et al. 1983)

\begin{tabular}{|c|c|c|c|c|c|c|}
\hline $\begin{array}{l}\text { Speed Class } \\
\text { (mph) }\end{array}$ & Jan & Feb & Mar & Apr & May & Jun \\
\hline 0 & 5.4 & 3.2 & 1.0 & 0.7 & 0.7 & 0.6 \\
\hline $1-3$ & 31.9 & 26.8 & 18.4 & 14.8 & 14.2 & 11.0 \\
\hline $4-7$ & 31.4 & 31.4 & 32.7 & 31.9 & 32.9 & 34.2 \\
\hline $8-12$ & 19.6 & 23.9 & 26.5 & 27.8 & 29.0 & 28.7 \\
\hline $13-18$ & 7.3 & 9.4 & 13.7 & 15.9 & 16.1 & 17.5 \\
\hline $19-24$ & 2.8 & 3.3 & 5.5 & 6.7 & 6.0 & 6.7 \\
\hline $25-31$ & 1.1 & 1.5 & 1.9 & 2.0 & 1.1 & 1.3 \\
\hline $32-38$ & 0.3 & 0.4 & 0.4 & 0.2 & 0.1 & 0.0 \\
\hline $39-46$ & 0.1 & 0.1 & 0.0 & 0.0 & 0.0 & 0.0 \\
\hline$>46$ & 0.0 & 0.0 & 0.0 & 0.0 & 0.0 & 0.0 \\
\hline Total (\%): & 100.0 & 100.0 & 100.0 & 100.0 & 100.0 & 100.0 \\
\hline Jul & Aug & Sep & Oct & Nov & Dec & Annual \\
\hline 0.4 & 0.8 & 1.4 & 3.1 & 5.5 & 6.8 & 2.5 \\
\hline 13.2 & 16.9 & 20.7 & 28.5 & 32.9 & 32.9 & 21.8 \\
\hline 37.8 & 38.6 & 37.4 & 35.2 & 32.0 & 29.9 & 33.8 \\
\hline 27.9 & 26.3 & 25.4 & 21.8 & 18.9 & 19.0 & 24.6 \\
\hline 14.3 & 12.5 & 10.8 & 7.9 & 6.9 & 7.1 & 11.6 \\
\hline 5.4 & 4.2 & 3.6 & 2.7 & 2.7 & 2.9 & 4.4 \\
\hline 0.9 & 0.7 & 0.7 & 0.7 & 0.9 & 1.1 & 1.2 \\
\hline 0.0 & 0.0 & 0.0 & 0.1 & 0.2 & 0.2 & 0.2 \\
\hline 0.0 & 0.0 & 0.0 & 0.0 & 0.0 & 0.1 & 0.0 \\
\hline 0.0 & 0.0 & 0.0 & 0.0 & 0.0 & 0.0 & 0.0 \\
\hline 100.0 & 100.0 & 100.0 & 100.0 & 100.0 & 100.0 & 100.0 \\
\hline
\end{tabular}




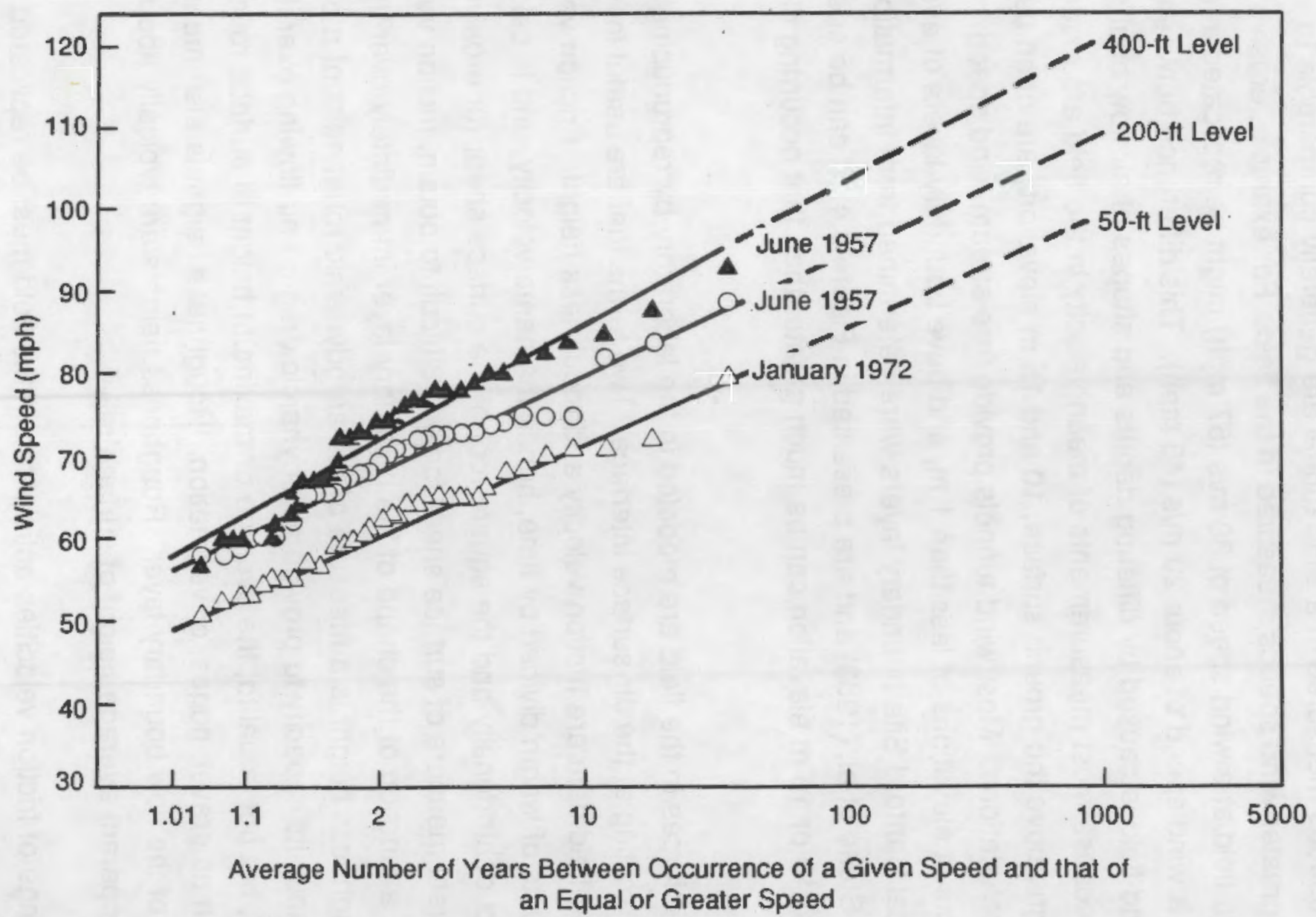

FIGURE 3.3 Peak Wind Gust Return Period Probability Diagram, Based on Records 1945 through 1980 (from Stone et al. 1983) 
(114 mph). Estimates of peak wind gusts for greater than 100-year-occurrence intervals are not considered reliable, but are included to provide a rough range for wind tunnel tests.

Wind speeds measured in a wind tunnel are generally comparable to significantly greater wind speeds measured in the field. For example, erosive forces present in the field at a wind speed of $30 \mathrm{~m} / \mathrm{s}(67 \mathrm{mph})$ might be replicated in a wind tunnel using a wind speed of about $20 \mathrm{~m} / \mathrm{s}(45 \mathrm{mph})$. This difference between laboratory and field is caused by differing depths and shapes of air flow boundary layers and because most measurements of mean velocity in the field are made at distances high above the ground surface; 10 and $15 \mathrm{~m}$ elevations are often used by meteorological stations. Most wind tunnels provide free-stream wind speed measurements at elevations of less than $1 \mathrm{~m}$, and have boundary layers of even less depth. Typical Hanford Site boundary layers were determined from information presented in Stone et al. (1983) and are presented in Figure 3.4. It can be seen that a wind speed at 10 or $15 \mathrm{~m}$ elevation can be much greater than that occurring closer to the ground.

Erosive forces in the field are modeled in the laboratory by reproducing the shear forces existing at the air-surface interface. Two terms that are useful for relating laboratory and field data are friction velocity and roughness height. Friction velocity is a term with units of length divided by time, hence the name velocity, and is calculated as the product of air density and the square root of the surface shear (or erosive) force. Because a direct measure of surface shear force is difficult to obtain, friction velocity is calculated as a function of the shape of the boundary layer immediately over the surface. Roughness height is a measure of the aerodynamic roughness of a particular surface, and thus its capacity to provide aerodynamic drag on air flowing over it. It is influenced by, but not equal to, the average or maximum height of surface roughness elements such as gravel, ridges, or vegetation. Roughness height is also measured as a function of the flow boundary layer. Roughness heights are typically about onetenth of the apparent average height of surface relief.

The range of friction velocities anticipated in the field must be replicated in the laboratory. Many typical roughness heights and friction velocities were summarized by Sehmel $(1980,1984)$ for various surfaces and wind speeds between 1 and $40 \mathrm{~m} / \mathrm{s}$. 


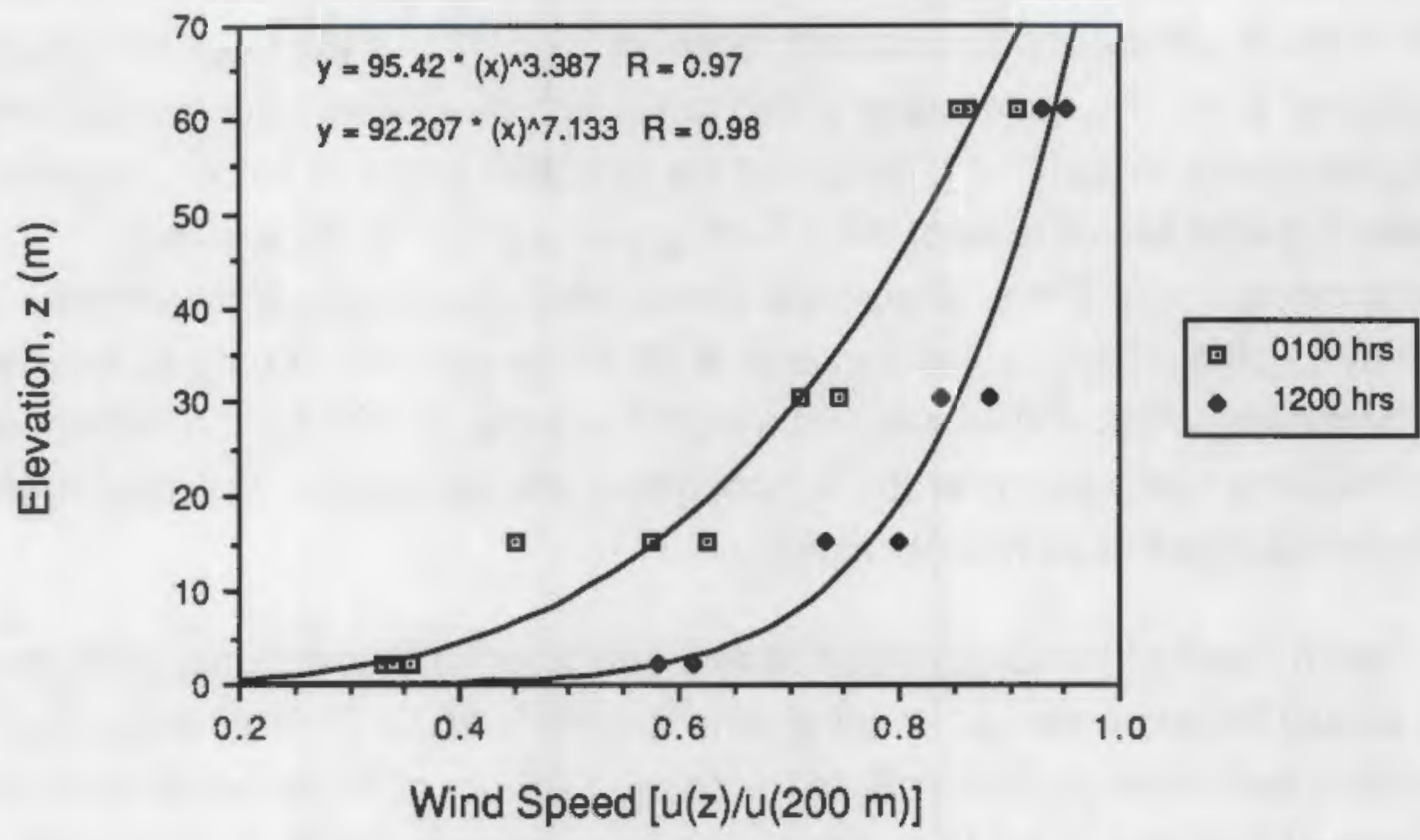

FIGURE 3.4. Typical Hanford Site Wind Speed Boundary Layers at 0100 and $1200 \mathrm{hr}$ (calculated after Stone et al. 1983)

Level desert was described to have a typical roughness height of $0.03 \mathrm{~cm}$. The friction velocity over such a surface was shown to be $1.81 \mathrm{~m} / \mathrm{s}$ for a mean wind speed of $40 \mathrm{~m} / \mathrm{s}(89 \mathrm{mph}$ ) measured at an elevation of $2 \mathrm{~m}$. Ligotke (1988) performed wind tunnel measurements over two types of soil and gravel mixtures that had been selected for possible use on protective barriers. The surfaces were weathered by exposure to high wind speeds before measurements were made of roughness height. The roughness height of a $30 \%$ mixture of $0.7-\mathrm{cm}$ gravel was shown to be $0.041 \pm$ $0.008 \mathrm{~cm}$, and that of a $30 \%$ mixture of $1.6-\mathrm{cm}$ gravel was shown to be 0.10 to $0.37 \mathrm{~cm}$. Because Sehmel's level desert classification was shown to be approximately aerodynamically similar to the $0.7-\mathrm{cm}$ gravel and soil surface, the range of friction velocities anticipated in the field on the Hanford Site may be determined.

Boundary layers for the Hanford Site (Figure 3.4) indicate that the magnitude of the mean wind speed at $2 \mathrm{~m}$ is approximately $1.5 \pm 0.2$ times less than that occurring at an elevation of $15 \mathrm{~m}$. However, this factor may be conservative because of possible 
boundary layer distortions during peak gust events. Assuming no boundary layer disturbance, the roughly approximated 10,000-year wind speed of $51 \mathrm{~m} / \mathrm{s}(114 \mathrm{mph})$ at $15 \mathrm{~m}$ would correspond to a velocity range of 30 to $42 \mathrm{~m} / \mathrm{s}$ (67 to $95 \mathrm{mph}$ ) at an elevation of $2 \mathrm{~m}$. The upper value of this range agrees well with the highest wind speed discussed by Sehmel (1984), and the indicated range of friction velocities required for wind tunnel tests of the $0.7-\mathrm{cm}$ gravel and soil surface is thus approximately 0 to $2.0 \mathrm{~m} / \mathrm{s}$. Figure 3.5 shows additional results of measurements made by Ligotke (1988). Measurements at $10 \mathrm{~m} / \mathrm{s}$ over a similar bare surface resulted in a roughness height of $0.49 \mathrm{~mm}$ and a friction velocity of $0.83 \mathrm{~m} / \mathrm{s}$. A friction velocity of $2.0 \mathrm{~m} / \mathrm{s}$ was developed over the $0.7-\mathrm{cm}$ gravel and soil surface at a wind tunnel freestream wind speed of $25 \mathrm{~m} / \mathrm{s}$ ( $56 \mathrm{mph}$ ).

As a result of this comparison of field and laboratory conditions, wind tunnel tests should therefore be performed at wind speeds to about $25 \mathrm{~m} / \mathrm{s}$. As surface roughness increases (for example, in the case of 1.6- $\mathrm{cm}$ or larger gravel or in the presence of vegetation) the test velocity should remain constant; however, the erosive

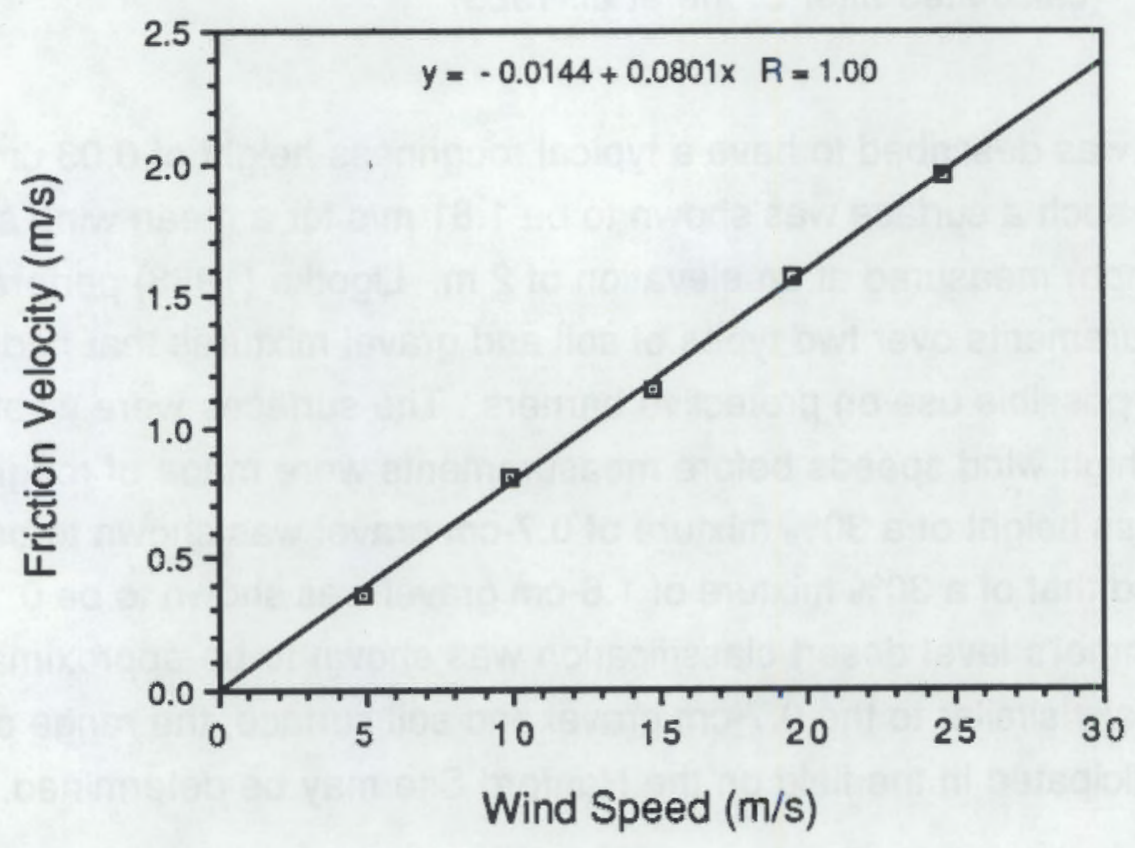

FIGURE 3.5. Friction Velocities Measured Over a Plastic Spray-Coated $30 \% 0.7-\mathrm{cm}$ Gravel and Soil Surface with a Roughness Height of $0.41 \pm 0.08 \mathrm{~mm}$ (from Ligotke 1988) 
forces during these tests will be greater that those during tests with the $0.7-\mathrm{cm}$ gravel surface because of greater aerodynamic drag of the rougher surfaces.

In addition to wind forces, precipitation and temperature cycles must be included in a predictive model of surface deflation. Both parameters influence the SMC of surface soil and the duration of time that surface soil remains moist following a precipitation event. Temperature and precipitation data display strong diumal and seasonal variations and are characterized for the Hanford Site in Stone et al. (1983).

\subsection{EXPERIMENTALDESIGN}

A series of wind tunnel tests are proposed to test the effects of eolian processes on the stability of the protective barner surface layer. These tests will be performed to determine the feasibility of using soil and gravel admixtures in the top layer of the protective barrier to reduce wind erosion and surface deflation, and to test the relative resistance to wind erosion of various admixtures. Deflation rates under extreme wind events will also be measured during these tests for subsequent modeling efforts.

Soil and gravel admixtures will be prepared by altering the concentration, particle size distribution, and shape (angular vs rounded) of gravel particles mixed with a silt-loam soil from the McGee Ranch. No tests are currently proposed using soil from Area 1 near the 200-West Area because this soil is no longer being considered for use by project engineers (primanily because of the much superior water retention capacity of the McGee Ranch soil). Soils under consideration for use in protective barrier construction have been characterized by Last et al. (1987).

Surface crusts are generally thought to provide a relatively stable surface; however, disturbed surface crusts may provide poor resistance to wind forces. Vegetation may provide a stabilizing cover under certain conditions, and even roots remaining in the soil in the aftermath of a range fire may add stability to the surface. However, sparse clumps of vegetation are speculated to have the opposite effect by inducing scouring wind velocities at the surface and potentially initiating the formation of large erosive structures such as blowouts. Burrowing animals may also provide a driving force for increased deflation of the barrier surface as they transport fresh soil to the surface where it dries and is subject to erosive forces. Under the initial influences of plants and animals, an initially flat terrain may develop relief structures that affect the 
stability of the surface. Finally, low SMC contributes to reduced surface stability by reducing the cohesive forces of water in voids between soil particles.

Although duplicating a soil that has evolved slowly in the field is difficult to achieve in a laboratory, experiments are planned to investigate the various components of the soil and gravel mixtures that are believed to be important with respect to wind erosion. By combining the results of all of the separately tested components, an overall description of wind erosion and the parameters that influence it will be developed. Tests relating wind tunnel conditions to field conditions are also proposed to provide additional data for validating the wind tunnel test procedures.

\subsubsection{Soil and Gravel Mixtures}

Four series of tests are planned to provide initial information on wind erosion over non-vegetated (bare-surface) proposed barnier surface mixtures, including soilonly, soil and single-particle-size gravel mixtures, soil and well-graded gravel mixtures, and soil and angular crushed-rock mixtures. These tests were initiated in FY87 and are planned to be continued during FY88 and FY89. Subsequent test series are planned to investigate the influences of soil moisture, surface crusts, vegetation, and other aspects of the barrier surface on wind erosion. Experiments performed during FY87 included McGee Ranch silt-loam soil mixed with 30 and $50 \%$ concentrations, by mass, of $0.7-\mathrm{cm}$ gravel ( 5 tests), and $30 \% 1.6-\mathrm{cm}$ gravel ( 1 test).

Seven or eight tests are scheduled to be performed in FY88, which will include the soil-only and the remaining planned soil and (single particle size) gravel mixtures. Tests planned for FY89 include five or nine surface mixtures of soil and well-graded gravels and three tests with angular crushed-rock and soil mixtures. Characteristics of the well-graded and crushed-rock mixture(s) will be determined following completion of testing and analysis of the soil and single-particle-size gravel mixtures. A test matrix has been developed to provide information on the four configurations by completing a minimum number of tests to conserve time and cost; it is possible that, after completing the tests, data analysis, and interpretation, additional tests will be required to further define the optimum surface configuration. These additional tests are not included in the project schedule (discussed in Section 5.1), but should be completed, if necessary, before specialized tests listed in that schedule are begun. 
Four surface configurations will be studied during tests of bare-surface, or nonvegetated soil and gravel mixtures. These include soil-only surfaces, gravel percentage and size, gravel size distribution, and gravel shape. Gravel percentage will be determined as the gravel mass fraction of the total soil, gravel, and water present in the mixture. Gravel size will be determined by sieve analysis and will be characterized by mass median diameter, geometric standard deviation, gravel type [i.e., (rounded) river gravel or (angular) crushed rock ], and bulk density. All but three tests will be conducted using river gravel rather than crushed rock. Soil density was $1.6 \mathrm{~g} / \mathrm{cm}^{3}$ during the FY87 tests, or approximately $90 \%$ of the maximum density. (This density is not dissimilar from densities of $>1.5 \mathrm{~g} / \mathrm{cm}^{3}$ that are anticipated as a result of the placement process during construction.) This density will also be used during subsequent tests, although densities of soil-only and low-gravel-percentage mixtures are anticipated to be less than $1.6 \mathrm{~g} / \mathrm{cm}^{3}$. In the field, the surface layer will likely be disturbed during seeding, and the originally compacted densities may then be reduced. Soil moisture content between 2 and $6 \%$ was measured during the FY 87 tests, and similar SMC will be provided for continuing tests. Limiting the number of parameters and the number of variations of each parameter will reduce the number of tests required to determine the effect of gravels on surface stability. The effects of vegetation, SMC, and other parameters will be determined using the most suitable mixture of soil and gravel in the subsequent series of tests described below.

Soil-only surfaces will be tested to provide data for a basis of comparison between the four primary types of measurements included in these initial tests: 1) soil only, 2) soil plus gravel, 3) soil plus well-graded gravel, and 4) soil plus angular crushed-rock gravel. The planned test matrix is shown in Table 3.2. In addition to the soil-only tests, the soil and gravel mixture surface tests will consist of McGee Ranch soil mixed with three concentrations of six or seven different types of gravel. Suggested gravel concentrations are 0 (soil-only), 10,30, and 50\%. Suggested gravel sizes are about $0.25,0.7,1.6$, and $3.0 \mathrm{~cm}$, one or two well-graded mixtures, and one crushed-rock mixture similar in particle size distribution to the first well-graded mixture or to one of the wind-resistant single-particle-size gravel mixtures. Not all combinations of parameters must be tested; if all combinations were tested, 34 tests might be required, including 12 replicate tests. Selected combinations of parameters will be tested to provide information on the relative resistance to wind erosion based on gravel size and concentration. A total of 20 to 26 tests, including 9 to 12 replicate 
TABLE 3.2. Proposed Tests of Bare-Surface Mixed Soil and Gravel Surfaces

\begin{tabular}{|c|c|c|c|c|c|}
\hline Test & Gravel Size & & Grav & entags & lass) \\
\hline configuration & (cm) & Soil-only & 10 & 30 & 50 \\
\hline $\begin{array}{l}\text { Soil-Only } \\
\text { (3 tests) }\end{array}$ & Soil-only & 3 & - & - & - \\
\hline $\begin{array}{l}\text { Soil/gravel } \\
\qquad(10 \text { or } 11 \text { tests) }\end{array}$ & $\begin{array}{l}0.25 \\
0.7 \\
1.6 \\
3.0\end{array}$ & $\begin{array}{l}- \\
- \\
-\end{array}$ & $\begin{array}{l}\text { (a) } \\
2 \text { (b) } \\
\text { (a) } \\
\text { (a) }\end{array}$ & $\begin{array}{l}1 \\
3 \text { (c) } \\
2 \text { (d) } \\
1\end{array}$ & $\begin{array}{l}\text { (a) } \\
2 \text { (c) } \\
\text { (a) } \\
\text { (a) }\end{array}$ \\
\hline $\begin{array}{l}\text { Well-graded } \\
\text { (5 or } 8 \text { tests) }\end{array}$ & $\begin{array}{l}\text { Mix } 1 \\
\operatorname{Mix} 2(e)\end{array}$ & - & $\begin{array}{l}1 \\
1\end{array}$ & $\begin{array}{l}3 \\
2\end{array}$ & $\begin{array}{l}1 \\
1\end{array}$ \\
\hline $\begin{array}{l}\text { Crushed-rock } \\
\text { (3 tests) }\end{array}$ & $\operatorname{Mix} 1(f)$ & - & - & 3 & - \\
\hline
\end{tabular}

(a) No test planned.

(b) Need to replicate test will be determined.

(c) Completed in FY87.

(d) One of two tests completed in FY87.

(e) Need for Mix 2 tests will be determined after data analysis.

(f) A single-size gravel such as $0.7 \mathrm{~cm}$ may be substituted pending analysis of preliminary results.

tests are expected to be required. The need to perform certain tests will be resolved pending analysis and interpretation of the primary tests involving mixtures of soil and single-size niver gravel. These primary tests should be performed for all gravel sizes at a gravel concentration of $30 \%$, and at all gravel concentrations for the $0.7-\mathrm{cm}$ gravel. Replicate tests have been performed previously of the 30 and $50 \%$ mixtures of $0.7-\mathrm{cm}$ gravel, and additional replicate tests may be required at the $10 \%$ mixture of the $0.7-\mathrm{cm}$ gravel and the $30 \%$ mixture of the 1.6- $\mathrm{cm}$ gravel to allow determination of the effect of gravel size. This will require 9 to 11 tests, including 6 primary and 3 to 5 replicate tests. In addition to these primary tests, 11 to 15 additional tests and replicate tests should be performed for the following conditions: soil-only, one or two well-graded gravel mixtures, and one crushed-rock mixture. These tests and replicates are 
planned to provide statistically valid information on the repeatability of test procedures and allow comparison between the four types of treatments.

The test matrix described above and shown in Table 3.2 is designed to allow statistical testing, based on a fixed-effects, one-way analysis of vaniance, of the effect of increasing soil gravel size when incorporated in soil at the $30 \%$ rate. Both linear and simple non-linear models can be fit if a functional relationship caused by gravel size is evident. In addition, the one-way analysis of variance could include the soilonly, well-graded, and crushed-rock treatments, both to supply additional degrees of freedom and to compare with soil and gravel mixture results.

The statistical analysis for gravel mass percentage at $0.7-\mathrm{cm}$ gravel size as well as for Mix 1 may be conducted concurrently or individually as outlined above. It is recognized that the data from several treatments (the soil-only, and two of the $30 \%$ gravel treatments) are used more than once in the suggested statistical treatment. Although this could result in some erroneous judgments of statistical significance (i.e., type I errors larger than the nominal $p<0.05$ ), the exploratory nature of the study leads us to believe the course outlined is best and will reduce the chance of failure to measure significant differences between various treatments. As tests performed in different years are potentially affected by surface preparation and measurement technique differences, and because the bare-surface series of tests requires more than one year of effort, the repeatability of test measurements from one year to another should be determined. The effect of year of test on repeatability can only be evaluated for one treatment with the proposed test matrix (1.6-cm gravel at $30 \%$, by mass). If results from this treatment are very different between different years of testing, additional replicates may be required.

Following completion of the initial soil and gravel surface tests, all data will be reduced and interpreted to determine the optimum combination of soil and gravel to minimize wind erosion. These results will be compared with needs of subsurface water storage and transport, plant growth (for transpiration), construction, availability of materials, and other factors to determine a likely candidate surface layer mixture. Subsequent tests of wind erosion will be made with this surface in combination with other surface characteristics to determine rates of deflation. These data will then be used with climatological conditions to model long-term surface deflation rates. 


\subsubsection{Surface Crusts and Soil Moisture Content}

The candidate design surface determined from non-vegetated soil and gravel mixture surface experiments will be tested for the influence of surface crusts and SMC on rates of deflation. The primary uses of these data include characterization of potentially increased rates of deflation caused by low SMC and measurements of deflation rates for various conditions for subsequent use as input to long-term predictive models. Surface crusts are anticipated to form and to protect the surface layer of the protective barrier by substantially reducing rates of deflation (reducing deflation rates by perhaps more than two orders-of-magnitude).

Three types of surface crusts are identified, physical, chemical, and biological. Physical crusts include wind-hardened, desert pavement, and crusts caused by rainfall and subsequent evaporation. Wind-hardened surfaces form over bare (no crust) surfaces during exposure to winds in the absence of rainfall. Desert pavement occurs when gravel becomes exposed at the surface, aligns under the forces of wind and gravity, and forms a cover over a substantial fraction of the surface area. Rainfall crusts are common and occur as rainfall dissolves soil aggregates, and later evaporates, leaving a hardened surface. Chemical crusts occur when salts are brought to the surface by water and later dry on the surface. Biological lichencryptogamic crusts are common in desert areas and form as a combination of algae and moss.

Tests completed previously included only wind-hardened surfaces at in situ-tolow SMC. No change in deflation rate was observed for SMC ranging from about 2.5 to $6 \%$. Future tests should verify this observation and test the design surface mixture over the range of low SMC anticipated. Because rates of deflation of surface crusts are primarily for model input, rather than to investigate a worst-case condition, limited tests will be performed. Crusts developed by rainfall and biological crusts are thought to be more significant than chemical and desert pavement crusts on the Hanford Site. Crusts are most easily obtained by removing natural surfaces from the field; however, it may be possible to create certain natural crusts in the wind tunnel or greenhouse. Six tests are planned to investigate the influence of SMC on surface deflation rates; two replicate tests will be performed at three SMC levels corresponding to in situ, low, and very low SMC. In situ levels are anticipated to be less than $10 \%$; however, the range of naturally occurring SMC in the surface of silt-loam soils on the Hanford Site is 
unknown at present. Tests of surface mixtures with very low SMC would replicate soil conditions anticipated to occur during extreme droughts. Drying is thought to cause surface mixtures to become increasingly susceptible to wind erosion. Six additional tests are planned to investigate surface crusts, including tests of three crusts formed from rainfall-impact, and three lichen-cryptogamic crusts.

\subsubsection{Vegetation}

A viable plant community is required to maintain evapotransporation to dry the barrier surface layer. A vegetated cover will also generally provide improved surface stability over bare surfaces. For example, grasses have long been used to stabilize surfaces such as sand dunes. In addition to increasing the height of boundary layers, a continuous plant canopy is speculated to protect the surface by creating a region of reduced velocity wind immediately over the surface, and possibly attenuating high velocity gusts before their impact with the ground. However, it is possible that sparse plant growth may have the opposite effect. Isolated plants will modity the air-flow patterns as eddies are formed to the lee of each plant. Surface soil may be scoured by high-velocity air directed to the ground upwind, to the sides, or in the wake of the plant, or airborne material may deposit to the ground in the vicinity of lowered velocities.

Information is needed about the influence of plants on soil erosion of the protective barrier surface for both relative rates of erosion for the candidate surface mixture and as input for predictive models. This influence is anticipated to be a function of plant species and plant density, and will be affected by range fires and other disturbances. Other influences of vegetation may include possible synergistic effect of plants on soil structure evolution, microflora, and organic matter content. A limited number of tests should be performed over the range of plant canopy compositions anticipated on the barrier surface. Four plant density tests should be performed, two each with average and maximum anticipated cover densities. These tests will provide information on surface protection under optimum conditions, and very low deflation rates are anticipated. Worst-case conditions should also be tested. The influence of individual (sparse) plants and of roots-only (plants burned) should be tested. Six tests of sparse plant cover should be performed, two with bunchgrass cover and four with sparse native shrubs. Four roots-only tests should be performed following the plant density tests to determine the influence of plant roots on deflation 
rates. These might be periormed by burning plants on the surfaces employed during the plant density tests. Fourteen plant tests are planned.

\subsubsection{Animal Burrow Mounds}

Loose soil brought to the surface by burrowing animals is a potential source of surface deflation over long periods of time. Work currently under way has indicated that a large volume of soil may be transported by animals on the Hanford Site.

Pending validation of these early estimates by field observation studies and computer simulation (BIOPORT code), physical tests of the susceptibility of soil mounds to wind erosion should be performed. Although the potential significance of this source of deflation depends primarily on the extent of animal burrowing, several characteristics of burrow mounds lead to the conclusion that they could provide an important route of surface deflation. The mounds are generally thought to be composed of dry soil, which is, at least initially, not protected by vegetation or surface crusts. Because the mounds can protrude above the elevation of the surrounding surface, vegetation, and protective gravel mulch, they are potentially exposed to higher wind forces and wind gusts. Soil composition (i.e., gravel and soil mixture and particle size distributions) may be altered in the burrowing animal mounds, so tests of wind erosion should be based on mound conditions and characteristics typical of those encountered in the field, adjusted for the design soil and gravel mixture.

Pending definition of typical mound characteristics, a series of approximately six wind tunnel tests are possible to define soil loss rates from animal mounds caused by wind erosion. Because of the large height of the mounds with respect to the depth of the boundary layer in a wind tunnel test section, a vertical velocity gradient may be expected over the mound unless a tubulent boundary layer is developed upwind of the mound. This may be done with roughness elements or a two-dimensional grid. To isolate the soil particle erosion occurning on the mound from that of the actual surface, the surface below the mound may be fixed with a protective spray crust, with the mound left untreated.

Measured deflation rates from fresh animal mounds should be provided as input to surface deflation models. Other necessary information would include volume of mounds formed per year, the influence of aging on the susceptibility of mounds to 
wind erosion, the animal species and specific burrowing activities, and the climatic conditions during seasonal mound-forming periods.

\subsubsection{Microterrain}

An initially flat protective barrier surface may, over a long period of time, develop a morphology including varied surface elevations. Causes of this change in surface form may include settling of lower layers of the protective barrier, the influence of wind and water forces on the vegetated surface, burrowing animals, or even frostheave cycles. The contribution of microterrain structures to the overall resistance of a surface to wind erosion cannot be assumed to be either positive or negative. Models representing this phenomena would need to consider simplified representations of common structures.

The first aspect of a study of the influence of microterrain on wind erosion should include an analysis of the morphology of natural analog sites. If common surface characteristics could be characterized with respect to shape and size, an approach to physically modeling the influence of the most common structures could be developed. Small-scale structures such as furrows in a plowed field may be characterized, categonized, and tested in a wind tunnel. A limited number of wind tunnel tests (about 12) of three or four microterrain structures are proposed.

Physically modeling the influence of large-scale structures such as sand dunes or blowouts provides a greater degree of difficulty. This problem is discussed in the following chapter on windborne deposition of sand.

\subsubsection{Field Comparison Tests}

The use of wind tunnels to physically represent actual field conditions was discussed in Section 2.5. Although many advantages of wind tunnel modeling exist, comparisons between wind tunnel and field should be made. These were initiated in FY87 by characterizing the use of coated surfaces to develop boundary layer profiles over exposed surfaces, and by developing methods of obtaining representative aerosol samples of suspended soil mass over an exposed surface. This work should be continued by investigating different surface layer characteristics and conditions and 
the influences of length of exposed surface, saltation (avalanching effect), turbulence, and multiple-direction wind vectors.

\subsection{IEST SURFACE PREPARATION}

Surfaces for use in wind tunnel tests will be prepared in shallow trays from soil and gravel mixtures. Deeper trays will be used for tests including a vegetative cover or plant roots; these trays will be located out of the air flow in the false floor of the wind tunnel test section. Mixtures will be packed into the trays to appropriate densities and weathered before wind erosion tests. The moisture content of test mixtures will be determined at the time of preparation and following testing. If proven feasible, electrical conductivity probes may be inserted in the test surfaces to provide a measure of soil moisture content during selected tests. Tests involving surface crusts will use manufactured crusts or actual crusts obtained in the field and transported to the laboratory. Surface crusts will be maintained in an adjacent greenhouse.

Soil and gravel mixing, test tray construction, surface preparation and storage, and pre-test weathering will be performed similarly to those activities described in the report of the initial wind erosion tests (Ligotke 1988) for tests with bare surfaces. Tests with vegetation and natural or artificial crusts may require slight procedural modifications to account for increased surface layer depth or other considerations.

\subsection{IEST PROCEDURES}

The wind tunnel test section will be prepared by placing boundary layer trays upwind of actual test trays. All edges will be configured to present the test surface with a uniform air-flow boundary layer; tray edges will be below the level of the surface to avoid scouring eddies. The surfaces of boundary layer trays will be fixed with a watersoluble plastic coating to provide appropriate flow boundary layers and to prevent soil particle suspension. The coating will be applied by aqueous-solution spray to achieve a thin plastic layer that will not mask the morphology of the microterrain. Air-flow characteristics will be measured over selected test surfaces to provide information for determining surface roughness heights and friction velocities. Primary measurements during tests will include one or both of two independent methods pending sufficient justification of either method: concentration of suspended soil particles above the trailing edge of the test surface, and bulk tray mass. Other measurements will include 
temperature, humidity, wind speed, sampling probe efficiency, threshold velocities of soil particle suspension, soil particle vertical mass concentration profile, and SMC.

Standard procedures for prepaning the wind tunnel test section, characterizing velocity profiles and boundary layers, and measuring environmental conditions will be similar to those described in the report of the initial wind erosion tests (Ligotke 1988). Tests of each surface will include measurements of deflation versus wind speed (primarily the higher wind speeds of 10 to $25 \mathrm{~m} / \mathrm{s}$ ) versus duration of exposure to wind forces. Threshold velocities will be measured as necessary duning selected tests by focusing the viewing volume of a remote single particle analyzer over the trailing edge of test surfaces and within the boundary layer. Isokinetic aerosol sampling probes will continue to be used when necessary, and measurements of bulk surface mass and SMC are expected to be primary measurements during all tests. Measurements of the vertical profile of suspended soil particle mass will be performed periodically to provide information on the percentage of the mass flux sampled by aerosol probes.

\subsection{DATA ANALYSES}

Analysis of data collected during wind tunnel tests will be completed sequentially. Instrument calibrations will be documented. Test conditions, including soil type, gravel size and percentage, soil and mixture water content, and environmental conditions, will be summarized. Air-flow characteristics will be determined: mean approach velocity will be tabulated, vertical boundary layer measurements over test trays will be reduced to provide roughness height and friction velocities, and horizontal velocity profiles will be reduced to indicate uniformity of erosive forces over the width of the surface. Sampling probe effectiveness data will be analyzed to determine the significance of losses. Vertical mass concentration profiles of suspended soil particles will be determined for various surfaces and wind speeds. Surface deflation rates will be determined by two methods; results of deflation measurements by bulk (non-aqueous) changes in tray mass will be compared to those determined by analysis of aerosol samples. Surface deflation will be compared with mean air speed, friction velocity, and duration of exposure to constant wind speeds. Soil moisture content measurements will be performed before and after wind tunnel tests using destructive sampling methods, and vertical soil moisture profiles will be measured during tests, as feasible, using a system of miniature electrical conductivity probes. 
Following completion of surface configuration tests, various surfaces will be compared with respect to their capability to resist wind erosion. The most promising surface configurations will be subject to a review for suitability with respect to water storage capacities, vegetation cover requirements, susceptibility to burrowing animals, and other factors. Leading candidate surfaces will then be subject to further tests, including the effects of vegetation, animal burrows, crusts, and microterrain structures. 


\subsection{SAND TRANSPORT AND DEPOSITION}

Wind forces are anticipated to be important among processes controlling the deposition of sand and the formation of large-scale eolian structures on the surface of the protective barrier. Investigations should be performed of the patterns (boundary layers) of wind over the barrier, including edge effects, as they relate to fine soil displacement by sand particles and sand dune or blowout formation. Initial studies and, if determined necessary, field and wind tunnel tests, are briefly described below.

Control methods such as windbreaks may be necessary to control wind forces and reduce the possibility of the formation of large eolian structures such as sand dunes and blowouts. Sand transport and deposition tasks present major challenges, primarily for reasons of scale and uncertainties in source material (sand) quantities and susceptibility to transport and deposition. These tasks will require additional study before suitable methods of investigation can be identified. Costs estimated for these tasks, presented in Section 5.0, should be considered preliminary.

\subsection{WIND PATIERNS: BOUNDABY LAYERS AND EDGE EFFECTS}

Wind forces are anticipated to have a major effect on the surface stability of the protective barrier and should be characterized for subsequent use in models predicting rates of mass fluxes both to and from the surface. An initial study should be performed to summarize existing Hanford Site data with respect to important wind characteristics such as direction, intensity, frequency, duration, and shape of the lower boundary layer. These data exist (Stone et al. 1983) or may be determined from existing data sets; however, they must be interpreted with respect to the special needs of barner predictive models, and climatic variability over extended periods should be addressed. In addition, estimates of boundary layer characteristics and edge effects should be performed. If determined important with respect to surface stability, wind tunnel studies of reduced-scale barrier shapes, possibly including the influences of upwind terrain and the use of windbreaks, should be identified and planned. A separate test plan, or one prepared as an attachment to this document, should be prepared describing the proposed wind tunnel tests. 


\subsection{EXPERIMENTAL DESIGN}

Sand transport calculations initiated in an unpublished study by Kasper and Glantz should be extended to provide information for predictive models. This may include field studies to measure wind boundary layers upwind of, at the edges of, and over full-scale protective barrier prototypes or similar structures on the 200 Area plateau, and to investigate possible source materials upwind of barrier locations along prevailing wind vectors. Potential sand fluxes to the barrier and deposition rates should be estimated to determine the influence of sand particle displacement on surface layer fine soil particles. Natural analogs of sand dunes and blowouts at the Hanford Site should continue to be studied for probable cause of formation, and this information should be compared with conditions determined from studies of wind forces and edge effects (Section 4.1) to determine potential areas where sand deposition or surface shear forces may act to encourage the formation of large-scale eolian structures. In addition to providing information for modeling efforts, these studies should include investigations of possible methods of controlling the formation of eolian features, with the eventual goal of reducing the possibility of their formation on the protective barrier surface. 


\subsection{FACILITIES AND PROJECT PLANNING}

This section describes the PNL wind tunnel and outlines the project schedule, estimated costs, and required reporting. Dates of completion were selected based on current knowledge of the impact of these tasks on other barriers development activities.

\subsection{WIND TUNNEL FACILITY}

Experiments conducted to date have been performed at a new wind tunnel facility. Future studies, specifically those on the influence of microterrain on wind erosion, may require use of outdoor, or field wind tunnels. Physical models of boundary layers over proposed above-grade protective barriers may also require the use of other wind tunnel facilities.

Wind erosion tests will be completed in the Aerosol Wind Tunnel Research Facility. This facility (Figure 5.1), located on the Hanford Site, contains an environmental wind tunnel in which air flow profiles and boundary layers are closely controlled. The facility is described briefly below; additional information about the facility, wind tunnel, and aerosol science capabilities can be found in Ligotke et al. (1986).

Wind speed, relative humidity, temperature, and lighting are controlled within the PNL wind tunnel. The $70 \mathrm{~m}^{3}$ wind tunnel is constructed of stainless steel, for ease of clean-up, except for the transparent Lexan ${ }^{\circledR}$ walls and ceiling of the primary test section. Three test sections are used for a variety of environmental and engineering projects. The wind tunnel is operated in either closed-loop (recirculating) or singlepass mode for airborne particles by use of a removable bank of HEPA filters in the return loop. This allows for simplified air-conditioning and yet retains the applicability of the wind tunnel for particle resuspension studies that require clean air at the inlet to the test section. Designed to contain hazardous and toxic materials, the wind tunnel may be operated under negative air pressure. Exhaust from the system is passed through scrubbers and sets of HEPA filters.

Air movement within the wind tunnel is maintained by a 1-m-diameter variable speed fan operated by a $30 \mathrm{v} d c$ motor. Wind speed profiles and boundary layers are 


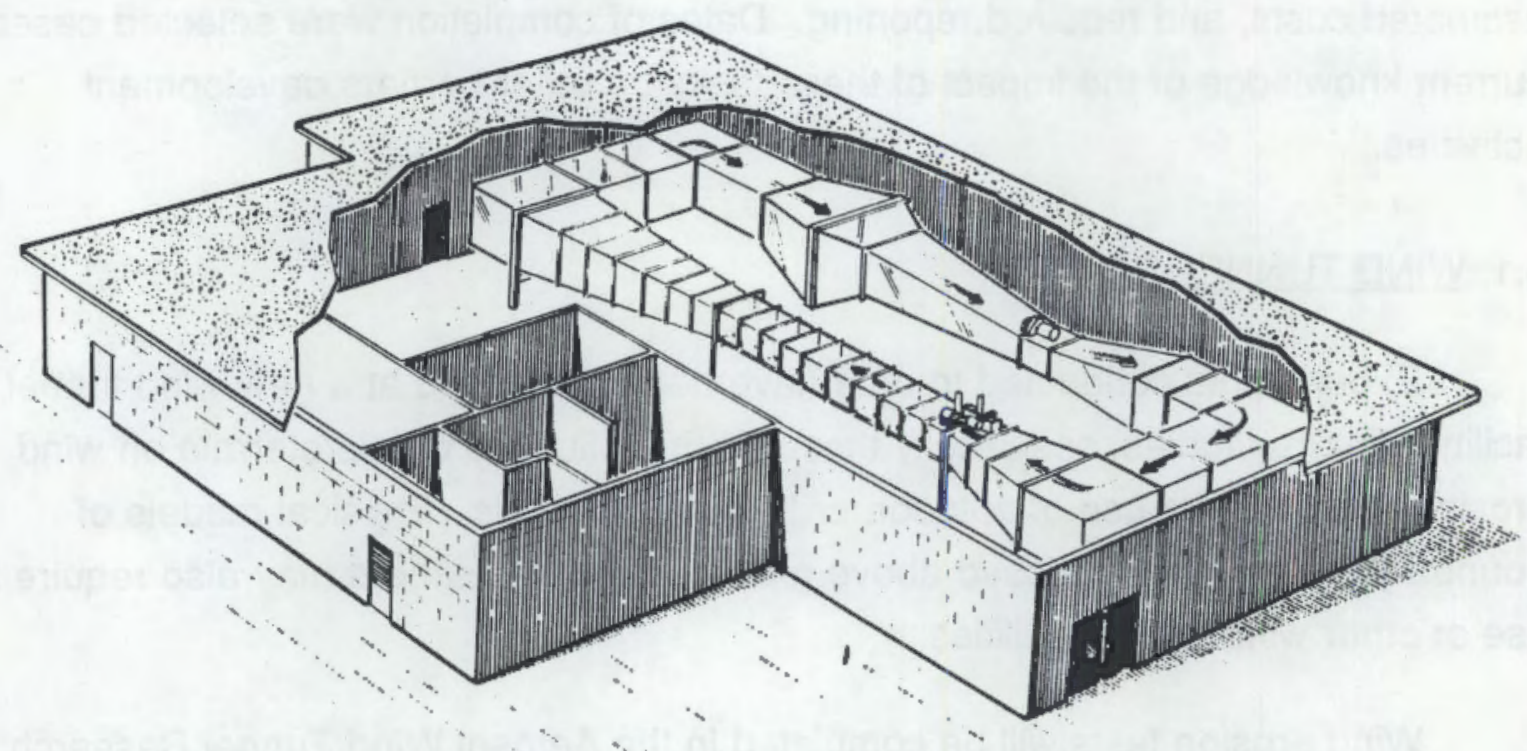

FIGURE 5.1 PNL Aerosol Wirid Tunnel Research Facility

uniform and controlled within the $0.61-\mathrm{m}$-square by $6.1-\mathrm{m}$-long test section used for all particle resuspension experiments. Maximum attainable velocity $30 \mathrm{~cm}$ above test surfaces is $31 \mathrm{~m} / \mathrm{s}$ (70 mph) under normal operating conditions; however, with modifications, velocities to $50 \mathrm{~m} / \mathrm{s}(120 \mathrm{mph})$ may be achieved. A reducing section at the inlet to the primary test section and turning vanes in all four bends limit upstream boundary layer depths and provide to the test section air flow having uniform horizontal and vertical velocity profiles. A $10-\mathrm{cm}$-deep false floor is provided below the aluminum plate floor of the test section. Trays used for wind erosion experiments are placed on top of the aluminum floor or within the false floor, depending on tray height. Roughness elements or actual surfaces coated with a surface fixative are placed upwind of the test surfaces to provide realistic boundary layers and to prevent scouring.

Environmental conditions are set and monitored as required for specific tests using a computer control and data acquisition system. The system is also connected 
to aerosol generators and measuring devices to provide a systematic method for test operation and data acquisition. Temperature is measured by thermocouples, and humidity is measured optically using chilled mirrors. Lighting for the test section is provided by $400-W$ metal halide lamps. Aerosol generators are available to produce a wide range of contaminants ranging from dust and ash to combustion products, acid fog, and mists. Aerosol charactenzation instrumentation is available to measure concentration, particle size distribution, and composition of a wide range of materials. Facility instrumentation includes a remote laser single-particle analyzer for nonintrusive measurements of particle concentration, size, and velocity.

\subsection{SCHEDULE AND COSTS}

Proposed tasks under this plan, including wind erosion and windborne-particle deposition are shown in Table 5.1. Details of each task are discussed above in Sections 3.0 and 4.0. Each test is a series of measurements, including air-flow boundary layer profiles and about 18 to 36 measurements of surface deflation. Provisions have not been made for additional tests that may be deemed important at some future date, but have not yet been identified.

The potential use of a portable field wind tunnel to provide additional comparisons between laboratory (wind tunnel) and field conditions has not been included in the present schedule or costs; however, this need will be considered during the experiments scheduled for FY89. Although a field experiment using a portable wind tunnel could provide useful data, it is anticipated to require a multi-year, high-cost effort to construct and operate a system that would provide meaningful data with respect to specific barrier development needs.

The level of funding estimated for wind erosion studies is estimated to be $\$ 732 \mathrm{~K}$ over six years. The original estimate made by Carlson in an unpublished test plan was $\$ 350 \mathrm{~K}$. Most of the increase is attributed to the addition of new tasks and greaterthan-anticipated per-test costs. The level of funding requested for studies of windborne transport and deposition (these tasks are listed separately from erosion/deflation tasks) is less certain at the present time as studies have yet to be initiated, however, the current estimate is $\$ 320 \mathrm{~K}$ over 2 years. 
IABLE5.1 Schedule and Costs for Protective Barrier Surface Stabilization Tasks

Task

Wind Erosion

Soil \& gravel mixtures 1

Soil \& gravel mixtures 2

Soil \& gravel mixtures 3

Field comparison

SMC \& surface crust

Plant canopy \& roots

Animal burrow mounds

Microterrain

\begin{tabular}{|c|c|c|}
\hline Description & Yearla) & Cost (\$K) \\
\hline 6 wind tunnel tests & FY87(b) & 42.4 \\
\hline $7-8$ wind tunnel tests & FY88(c) & 80.0 \\
\hline $8 \cdot 12$ wind tunnel tests & FY89(d) & 105.0 \\
\hline WT \& field measurements & FY89 & 105.0 \\
\hline 12 wind tunnel tests & FY90(e) & 120.0 \\
\hline 14 wind tunnel tests & FY90(e) & 115.0 \\
\hline 6 wind tunnel tests & FY91(e) & 40.0 \\
\hline 12 wind tunnel tests & FY91(e) & 110.0 \\
\hline Burrow/microterrain report & FY92 & 15.0 \\
\hline
\end{tabular}

Study and field investigation

Study and field investigation

FY90

60

FY91 75

Study

FY90

50

Wind tunnel scale modeling

Sunface Stability Models

Contribute to other Barriers Project modeling efforts

FY87 - FY92

\footnotetext{
(a) Based on current project priorities and funding levels.

(b) FY87 task has been completed.

(c) FY88 funding includes 8 wind erosion tests, and preparation of a final report of FY87 tests, and this test plan.

(d) Includes preparation of a final report (FY88 \& FY89).

(e) Dependent on completion of soil and gravel mixture tasks.

(f) Need to be determined in FY90.
} 
Costs include manpower and materials; capital expenses requirements have not been identified as of the current date. Some studies will require input from earlier tests and other portions of the protective barriers project prior to their initiation. Costs are approximate and depend on the ability to perform each task within a given fiscal year.

\subsection{REPORTING}

A series of reports will be prepared as selected milestones are achieved to describe results of the tasks described above. It is important that data be interpreted in a timely manner, the results reviewed, and all conclusions published for use by the barrier development program team, and also to provide documented methods and procedures used in developing portions of the protective barrier system.

A preliminary report on the first six wind tunnel soil and gravel tests has been prepared (Ligotke 1988) and should be followed by a second report in FY89 describing all results of the important baseline tests of soil-only, and soil and singleparticle-size gravel, well-graded gravel, and angular (crushed-rock) gravel. Subsequent reports of surface deflation tasks will include field/laboratory comparison (mid-FY90), SMC/crust/vegetation (mid-FY91), and burrows/microterrain (mid-FY92). Topics and target completion dates for reports describing the windborne deposition tasks will be determined at a later date. 


\subsection{SAFETY AND QUALITY ASSURANCE}

All laboratory and field work procedures will be performed safely using standard PNL safety and quality assurance procedures. Safe working procedures, habits, and conditions will be the priority of all work. No unusual safety hazards are anticipated during the completion of this work. No toxic or hazardous materials are anticipated to be required for activities suggested in this test plan.

Data will be entered into a series of controlled, bound laboratory notebooks issued by PNL. Each notebook will be labeled "Barriers" on the spine. Entries will include notes, design sketches, minor procedural modifications, data, and other relevant information. All entries will be dated and signed, and checked by the responsible task leader. Data collected or transferred to computer disk will be backedup by a hard copy located in a three-ring binder clearly marked by the number of the corresponding laboratory notebook. In addition to computer files, numerous data sheets will be required for each wind tunnel test. These data sheets, containing unreduced data, will be bound yearly and marked by the number of the corresponding laboratory notebook. Notebooks and three ring binders will be maintained at the laboratory or at the office of the task leader. At no time shall the custody of the notebooks or the three-ring binders be issued to separate individuals. After completion of each test series, one copy of all data sheets and calculation sheets will be made, bound, and stored in an alternate location. This location is currently designated as the $331 \mathrm{H}$ Building in the 300 Area.

Instrument calibrations will be required during wind tunnel tests. Procedures and data will be documented in the PNL notebooks. Calibration standards will be traceable to standards sufficient for project needs based on determination of required levels of accuracy. 


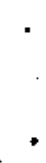

. 


\subsection{REFERENCES}

Adams, M. R., and N. R. Wing. 1986. Protective Barrier and Warning Marker System Develooment Plan. RHO-RE-PL-35P, Rockwell Hanford Operations, Richland, Washington.

Bagnold, R. A. 1941. The Physics of Blown Sand and Desert Dunes. Methuen and Co. Ltd., London.

Borrmann, S., and R. Jaenicke. 1987. "Wind Tunnel Expeniments on the Resuspension of Sub-micrometer Particles from a Sand Surface." Atmospheric Environ, 21(9):1891-1898.

Cal, S., F.F. Chen, and S.L. Soo. 1983. "Wind Erosion into a Porous Storage Pile and Use of Barriers." Environmental Science and Technology 17-5:298-305.

Chen, F.F. and S.L. Soo. 1983. "A Numerical Model for Steady Nonpoint Source Dispersion of Wind-Blown Fine Particles from Storage Piles and Experimental Study." Particulate Science and Technology 1:165-181.

Chepil, W. S. 1945a. "Dynamics of Wind Erosion: I. Nature of Movement of Soil by Wind." Soil Sci, 60:305-320.

Chepil, W. S. 1945b. "Dynamics of Wind Erosion: II. Initiation of Soil Movement." Soil Sci, 60:397-411.

Chepil, W. S. 1950. "Properties of Soil Which Influence Wind Erosion: I. The Governing Principle of Surface Roughness." Soil Sci. 69:149-162.

Chepil, W. S., and R. A. Milne. 1941. "Wind Erosion of Soil in Relation to Roughness of Surface." Soil Sci, 52:417-431.

Chepil, W. S., and N. P. Woodruff. 1963. "The Physics of Wind Erosion and its Control." Advances in Aroon, 211:302.

Chepil, W. S., D. V. Armbrust, and F. H. Siddoway. 1964. "Effects of Ridges on Erosion of Soil by Wind." Soil Sci. 28:557-560.

Fairchild, C. I., and M. J. Tillery. 1982. "Wind Tunnel Measurements of the Resuspension of Ideal Particles." Atmospheric Environ. 16:229-238.

Heinsohn, R.J. and M.H. Megherhi. 1986. "Control of Fugitive Dust by Windbreaks," Particulate Science and Technology 4:87-112.

Last, G. V., M. A. Glennon, M. A. Young, and G. W. Gee. 1987. Protective Barrier Materials Analysis: Fine Soil Site Characterization. PNL-6314, Pacific Northwest Laboratory, Richland, Washington. 
Ligotke, M. W. 1988. Soil Erosion Rates from Mixed Soil and Gravel Surfaces in a Wind Tunnel: A Preliminary Report. PNL-6677, Pacific Northwest Laboratory, Richland, Washington.

Ligotke, M. W., D. A. Cataldo, P. Van Voris, and C. A. Novich. 1986. "Analysts use Wind Tunnel to Study Particle Behavior in the Environment." Besearch and Development. T. M. Kelly, Barnington, Illinois.

Logie, M. 1981. "Wind Tunnel Experiments on Dune Sands." Earth Surfaces Process and Landforms 6:365-374.

Logie, M. 1982. "Influence of Roughness Elements and Soil Moisture on the Resistance of Sand to Wind Erosion." In Aridic Soils and Geomorphic Processes, ed. D. H. Yaalon, pp. 161-173.

Sehmel, G. A. 1984. "Deposition and Resuspension." In Atmospheric Science and Power Production. DOE/TIC-27601, pp. 533-583, National Technical Information Center, Office of Scientific and Technical Information, Oak Ridge, Tennessee.

Sehmel, G. A. 1980. "Particle Resuspension: A Review." Environmental Int. 4:107-122.

Stone, W.A., J.M. Thorp, O.P. Giftord, D.J. Hoitink. 1983. Climatological Summary for the Hanford Area. PNL-4622, Pacific Northwest Laboratory, Richland, Washington.

U. S. Department of Energy (DOE). 1987a. Interim Hanford Waste Management Plan. U.S. Department of Energy, Washington, D.C.

U. S. Department of Energy (DOE). 1987b. Final Environmental Impact Statement: Disposal of Hanford Defense High-Level, Transuranic, and Tank Waste. DOE/EIS0113 , U.S. Department of Energy, Washington, D.C.

Zingg, A. W. 1949. "A Study of the Movement of Surface Wind." Agriculture Engineering. 30(1):11-13. 


\section{DISTRIBUTION}

No. of

Copies

OFFSITE

2 DOE Otfice of Scientific and Technical Information

\section{ONSITE}

7 DOE Richland Operations Office

G. L. Bracken

J. J. Broderick

R. D. Freeburg

R. E. Gerton

R. D. Izatt

G. W. Rosenwald

J. P. Sands

26 Westinghouse Hanford Company

M. R. Adams

L. C. Brown

J.W. Carnmann

R. A. Carlson

H. F. Daugherty

K. A. Gasper

W. F. Heine

J. M. Henderson

G. W. Jackson

K. N. Jordan

D. S. Landeen

R. E. Lerch

H. E. McGuire

K.W. Owens

P. C. Payne

K. L. Petersen

S. J. Phillips

J. F. Relyea

R. C. Roos

R. C. Routson

W. W. Schulz

S. A. Weigman
No. of

Copies

QNSITE (con't)
N. R. Wing
D. D. Wodrich
R. D. Wojtasek
D. E. Wood

41 Pacific Northwest Laboratory

L. L. Cadwell

M. D. Campbell

D. A. Cataldo

J. L. Downs

J. W. Falco

M. J. Fayer

M. G. Foley

H. D. Freeman

G. W. Gee (2)

P. C. Hays

T. L. Jones

C. T. Kincaid

R. R. Kirkham

D. C. Klopfer

G. V. Last

M. W. Ligotke (7)

S. O. Link

G. P. O'Connor

W. H. Rickard

L. E. Rogers

R. L. Skaggs

J. A. Stottlemyre

G. P. Streile

J. M. Thomas

R. L. Treat

P. Van Voris

W. J. Waugh

R. E. Wildung

Publishing Coordination

Technical Report Files (5) 
